\title{
Integrated economic and environmental building classification and optimal seismic vulnerability/energy efficiency retrofitting
}

\author{
Martina Caruso $^{1} \cdot$ Rui Pinho $^{2}$ (D) Federica Bianchi $^{3} \cdot$ Francesco Cavalieri $^{3}$. \\ Maria Teresa Lemmo ${ }^{4}$
}

Received: 20 October 2020 / Accepted: 8 April 2021 / Published online: 28 April 2021

(C) The Author(s) 2021

\begin{abstract}
A life cycle framework for a new integrated classification system for buildings and the identification of renovation strategies that lead to an optimal balance between reduction of seismic vulnerability and increase of energy efficiency, considering both economic losses and environmental impacts, is discussed through a parametric application to an exemplificative case-study building. Such framework accounts for the economic and environmental contributions of initial construction, operational energy consumption, earthquake-induced damage repair activities, retrofitting interventions, and demolition. One-off and annual monetary expenses and environmental impacts through the building life cycle are suggested as meaningful performance metrics to develop an integrated classification system for buildings and to identify the optimal renovation strategy leading to a combined reduction of economic and environmental impacts, depending on the climatic conditions and the seismic hazard at the site of interest. The illustrative application of the framework to an existing school building is then carried out, investigating alternative retrofitting solutions, including either sole structural retrofitting options or sole energy refurbishments, as well as integrated strategies that target both objectives, with a view to demonstrate its practicality and to explore its ensuing results. The influence of seismic hazard and climatic conditions is quantitatively investigated, by assuming the building to be located into different geographic locations.
\end{abstract}

Keywords Building renovation - Life cycle assessment - Life cycle cost analysis · Environmental impact assessment $\cdot$ Seismic loss estimation $\cdot$ Retrofitting strategies $\cdot$ Costbenefit analysis

Rui Pinho

rui.pinho@unipv.it

Extended author information available on the last page of the article 


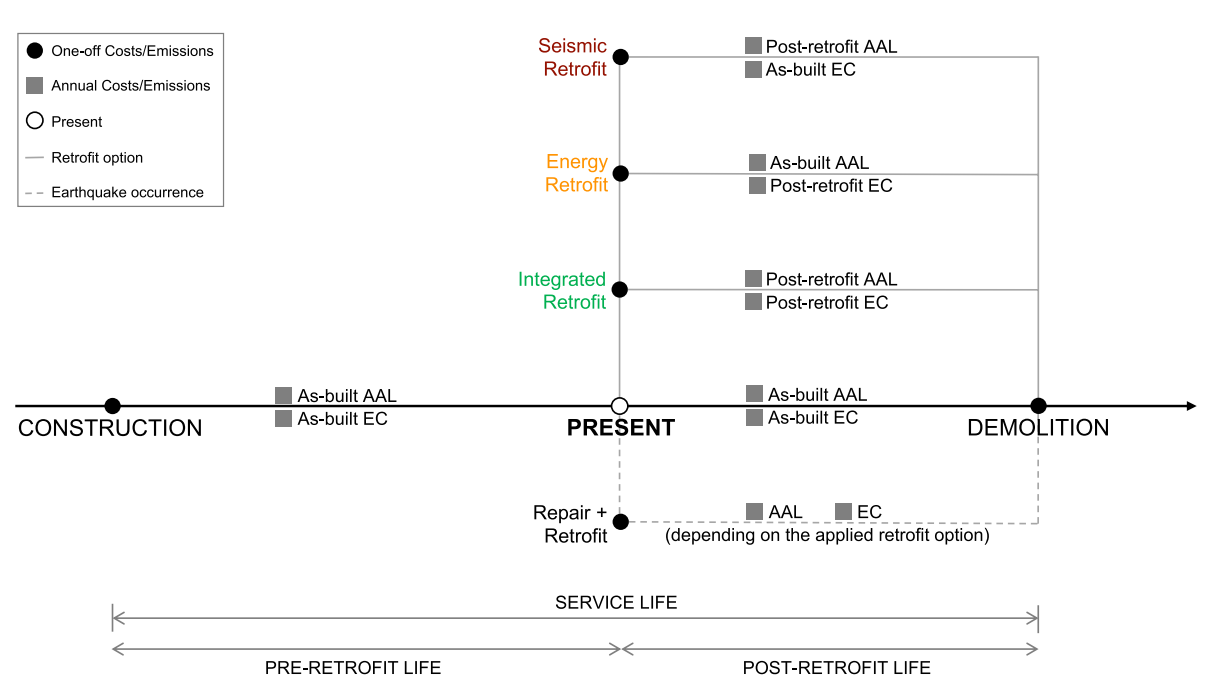

Fig. 1 Overview of the life cycle stages included within the proposed framework from construction to demolition, considering both one-off and annual expenses and emissions (Caruso et al. 2020a)

\section{Introduction}

A life cycle methodology for an integrated classification system for buildings and the identification of renovation strategies that lead to an optimal balance between reduction of seismic vulnerability and increase of energy efficiency of a building, considering both economic losses and environmental impacts, was proposed in Caruso et al. (2020a). In the present manuscript, the detailed and illustrative application of such framework to a casestudy building is in turn carried out, with a view not only to further demonstrate its practicality, but also to explore and discuss its ensuing results.

The scheme in Fig. 1 shows the temporal distribution and the main characteristics of the modules included within the framework, each representing a different life cycle phase of the building. The 'present time' is specified since: (1) the processes of actualisation and capitalisation at the current-time monetary value are necessary to make monetary costs financially comparable; and (2) in case of building renovation, whether an earthquake occurred or not, the time of intervention can affect the total monetary expenses and environmental impacts within the building life cycle. 'Present' can thus be referred to a generic time of assessment, the time to decide whether to renovate the building or not, or even to an earthquake occurrence, followed by the building renovation.

As shown in Fig. 1, the building life cycle stages included in the framework are: initial construction, operational use phase in the pre-retrofit configuration, retrofitting intervention, operational use phase in the post-retrofit configuration, and demolition. The operational use phases in both as-built and post-retrofit configurations include building energy consumption, estimated through energy performance analyses, and earthquake-induced damage and repair activities, evaluated through seismic loss assessment, in the as-built and post-retrofit configurations, respectively. The assessment of the as-built configuration is influenced by the architectural and structural characteristics of the building, e.g. structural type, material properties, envelope layers, transparent elements, etc. Conversely, the assessment of post-retrofit configurations is strictly related to the adopted retrofit type and 
to its effectiveness (for instance, if a sole energy refurbishment is provided, the energy needs of the building will decrease, whilst the impacts due to seismic hazard will remain unchanged, or even increase due to the higher value of the energy-retrofitted building).

Each of the modules can be implemented individually (or in groups, depending on the user needs) through available up-to-date methods to attain the corresponding task, e.g. seismic loss estimation can be performed through the refined FEMA P-58 approach (ATC 2018a, b) or any other existing methods (e.g. the simplified approach proposed by Cosenza et al. (2018) and prescribed in the Italian Guidelines for Seismic Risk Classification (MIT 2017)). For instance, if multiple energy refurbishments for a single building are investigated, modules referring to earthquake-induced damage repair activities can be excluded from the calculation.

The contributions to life cycle costs and carbon emissions of the life cycle phases considered are normalised with respect to the service life and the floor area of the building of interest, and then summed up. The summation, in terms of an annual Life Cycle Performance Metric (LCPM), i.e. either Total Annual Costs ( $€ / \mathrm{m}^{2}$ year) or Total Annual Emissions $\left(\mathrm{kg} \mathrm{eCO}_{2} / \mathrm{m}^{2}\right.$ year), is thus calculated as follows:

$$
L C P M=\frac{C+\left(A A L_{\text {as-built }}+E C_{\text {as-built }}\right) \cdot S L_{1}+R I+\left(A A L_{\text {post-retrofit }}+E C_{\text {post-retrofit }}\right) \cdot S L_{2}+D}{F A \cdot S L}
$$

including, (1) one-off costs or emissions due to Construction, Retrofitting Intervention and Demolition, indicated with $C, R I$ and $D$, respectively; (2) Average Annual Losses in terms of either monetary losses or carbon emissions due to seismic hazard, estimated before and after the retrofitting intervention, indicated with $A A L_{\text {as-built }}$ and $A A L_{\text {post-retrofit }}$, respectively; (3) annual monetary expenses and carbon emissions due to the building Energy Consumption, evaluated before and after the retrofitting intervention, indicated with $E C_{a s-b u i l t}$ and $E C_{\text {post-retrofit }}$, respectively; those being calculated through the pre-retrofit and post-retrofit Service Life of the building, indicated with $S L_{1}$ and $S L_{2}$, respectively, and normalised by the total service life $(S L)$ and the total Floor Area $(F A)$ of the building.

The proposed framework can serve for multiple purposes. For instance, it may constitute the basis for an integrated classification scheme, based on the building's life cycle economic and environmental impacts considering both its seismic vulnerability and energy consumption, as shown in Fig. 2, which may be of interest to compare costs and impacts associated to past, present and future constructions, but also for comparisons between different building typologies (e.g. reinforced concrete frames, masonry or steel structures, and so on). Such classification would hopefully go beyond the traditional and independent energy and seismic classification systems, encouraging a combined reduction of the economic and environmental impacts of the building stock. Figure 2 shows the results for the illustrative example described in Caruso et al. (2020a) for each retrofitting option and geographic location considered, i.e. (1) a highly seismic site, with warm weather ('Warm_ HighEq'); (2) a site with average seismic and climatic characteristics ('Mild_AvgEq'); and (3) a very cold site, with low seismic hazard ('Cold_LowEq'). It is a conceptual plot where the correspondence between cost/emission value ranges and the colour scale is purely demonstrative; a more extensive parametric study would need to be carried out in order to define appropriate ranges of values for each one of the classes.

As a second possible application of the proposed framework, monetary expenses and environmental impacts evaluated for the post-retrofit building's life can be used as performance metrics for the identification of the optimal retrofitting strategy for the building of interest, i.e. the one corresponding to the highest integrated reduction of post-retrofit costs 
Fig. 2 Plot of total annual costs and emissions for all illustrative application cases discussed in Caruso et al. (2020a), superimposed on a potential seismic vulnerability-energy efficiency integrated classification scheme. Note: The correspondence between cost/emission value ranges and the colour scale in this plot is purely demonstrative

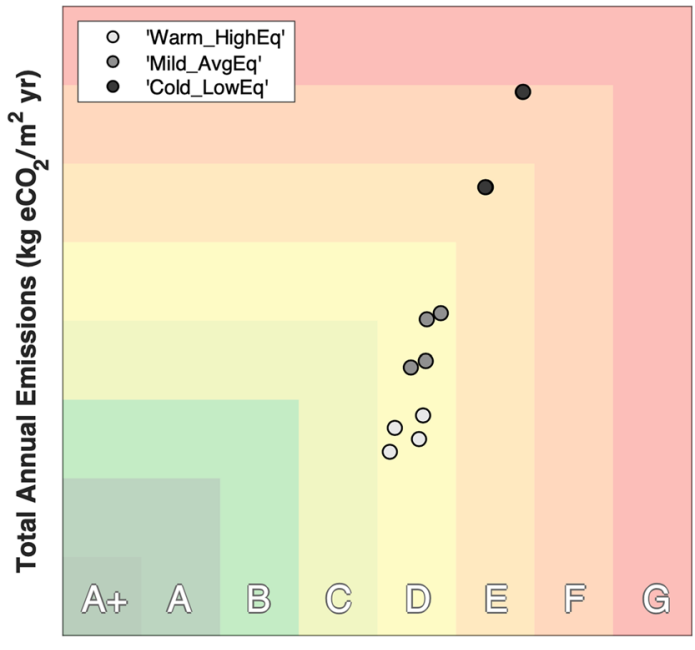

Total Annual Costs $\left(€ / \mathrm{m}^{2} \mathrm{yr}\right)$

and impacts. As will be shown later in this paper, the payback period of the retrofitting intervention and the average loss of life due to earthquakes can then constitute additional decision-making support tools for the identification of the optimal solution for the building under scrutiny.

A parametric study is thus performed herein, (1) considering multiple retrofitting options, including structural retrofitting, energy refurbishment, and integrated strategies; (2) calculating post-retrofit savings in terms of annual costs and emissions due to seismic hazard and energy consumption depending on the real effectiveness of each retrofitting strategy; and (3) varying the geographical location of the building.

\section{Case-study description}

\subsection{Building characteristics and properties}

The case-study under scrutiny (indicated with a red outline in Fig. 3) is a school building located in Isola del Gran Sasso d'Italia in Central Italy.

Although the original design documents were not available, comprehensive reports of in-situ inspections and material tests suggest that the school complex was built between 1960 and 1970 (Prota et al. 2015). The two adjacent structures to the building are separated by expansion joints and were thus assumed not to affect its seismic response.

The case-study building is composed of two rectangular sections with two aboveground storeys and a relatively small basement at one end of the structure (Fig. 3). The two above-ground storeys have a floor area of approximately $630 \mathrm{~m}^{2}$ and inter-storey heights of around 3.75 and $4.25 \mathrm{~m}$, respectively, and they are mainly intended for classrooms. The basement has a floor area of approximately $135 \mathrm{~m}^{2}$ and an inter-storey height of around $3.75 \mathrm{~m}$, and it mainly houses storage and mechanical rooms. The total floor area is approximately equal to $1400 \mathrm{~m}^{2}$, and the above-ground height is equal to about $8 \mathrm{~m}$. The structure is composed of sixteen Reinforced Concrete (RC) frames 
PRODUCED BY AN AUTODESK STUDENT VERSION

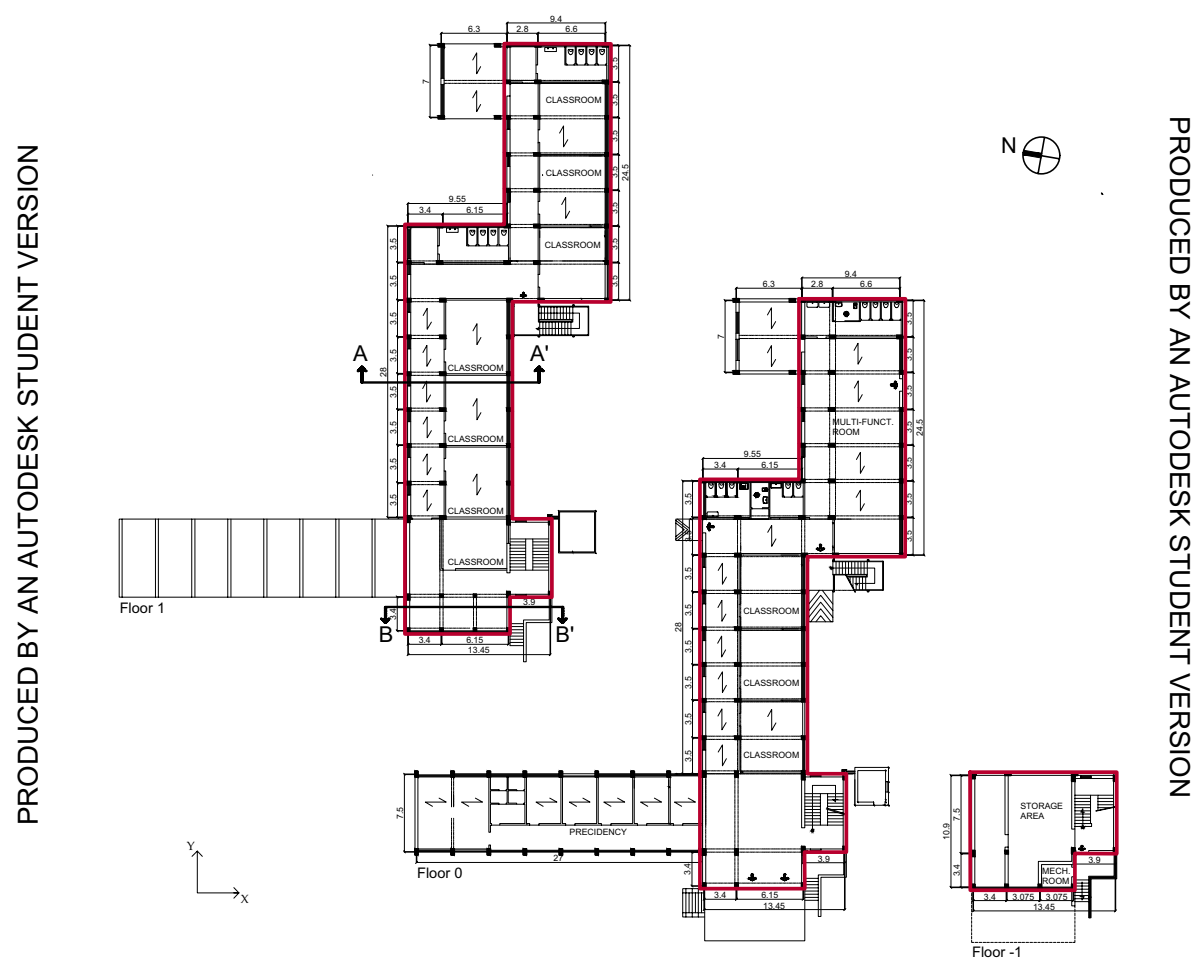

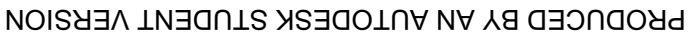

Fig. 3 Floor layouts of the three-storey school building (the part of the building considered as case-study in this paper is indicated with a red line) (Prota et al. 2015)

along the shortest direction $\mathrm{X}$, perpendicular to the orientation of slabs, as illustrated in the floor layouts in Fig. 3. The average spacing between two subsequent frames is approximately equal to $3.5 \mathrm{~m}$, and the bays are around $6 \mathrm{~m}$ long in the classrooms and $3 \mathrm{~m}$ long elsewhere. The most recurring column section is $200 \times 600 \mathrm{~mm}$, being mostly oriented in direction $\mathrm{X}$. The most recurring beam section is also $200 \times 600 \mathrm{~mm}$, though a few $200 \times 300 \mathrm{~mm}$ sections are also present. The one-way slabs consist of concrete and hollow clay blocks mixed floors, whilst the external infills are made of double-leaf masonry (with solid clay bricks in the external leaf and hollow ones in the internal one, separated by an air cavity), and the internal partitions are made of hollow clay bricks. The exterior infills present large openings all along the height of the building. The U-shaped staircase is composed of columns and beams supporting RC slabs, and its location in plan produces an eccentricity within the building. Figure 4 illustrates the most relevant elevations and sections of the case-study. 
PRODUCED BY AN AUTODESK STUDENT VERSION

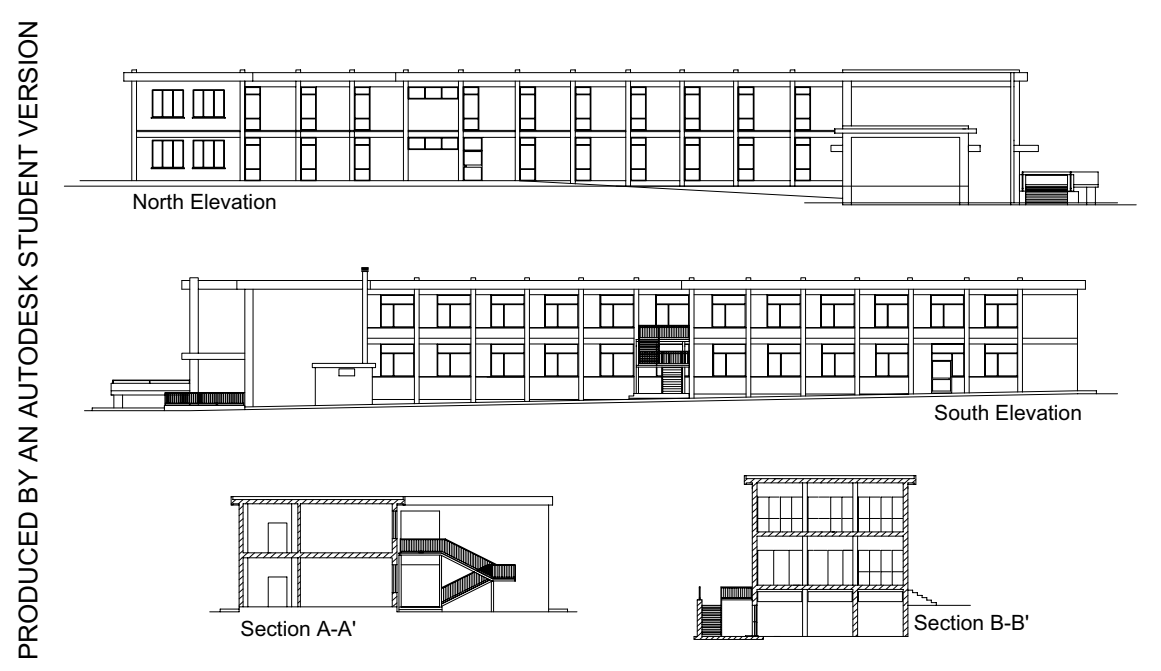

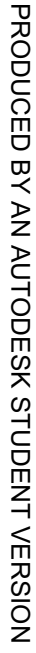

NOISY $\exists \wedge \perp N \exists O \cap \perp S$ YS $\exists O O \perp \cap \forall N \forall \wedge$ A $\exists \exists O \cap 0 O Y d$

Fig. 4 Relevant elevations and sections of the three-storey school building (Prota et al. 2015)

\subsection{Numerical modelling and structural analysis}

Based on the available information on the building, a 3D nonlinear numerical model of the case-study (Fig. 5) was developed with the fibre-based analysis software SeismoStruct (Seismosoft 2021). Two materials were defined: (1) existing concrete, with an average cylindrical compressive strength equal to $16.6 \mathrm{MPa}$ and an elastic modulus equal to

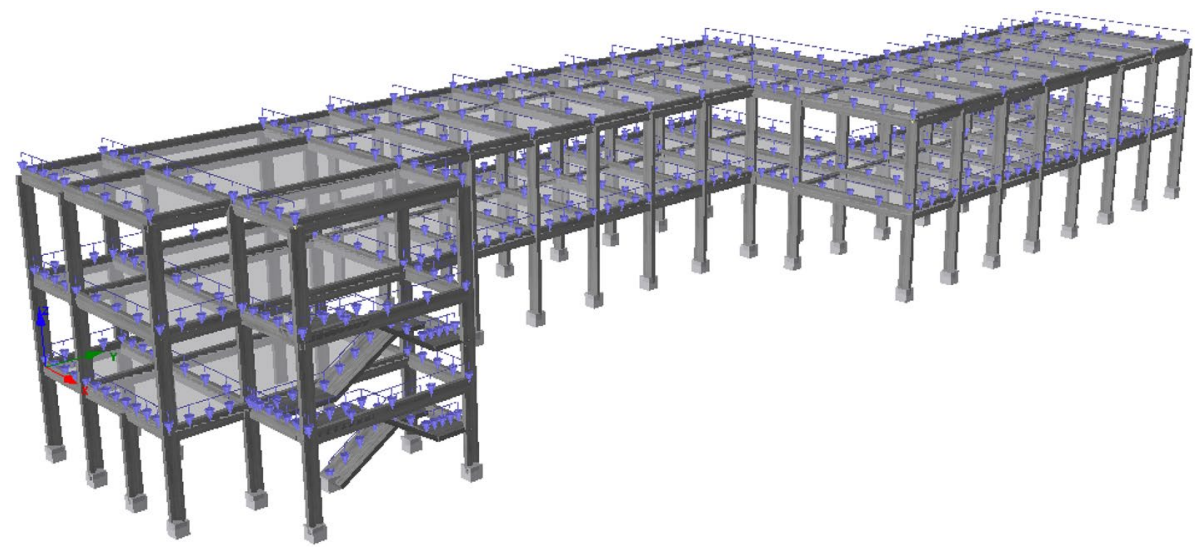

Fig. 5 Overview of the 3D nonlinear model built on SeismoStruct 
Table 1 Periods of vibration and participating masses corresponding to the first three modes

\begin{tabular}{lccccl}
\hline & T (s) & Mx (\%) & My (\%) & Rz (\%) & Type \\
\hline Mode 1 & 0.58 & 0.10 & 88.30 & 0.32 & Transl. Y \\
Mode 2 & 0.45 & 38.50 & 0.46 & 50.90 & Torsional \\
Mode 3 & 0.26 & 47.50 & 0.10 & 37.90 & Transl. X \\
\hline
\end{tabular}

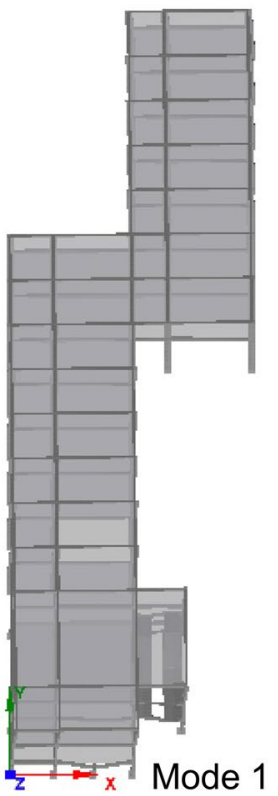

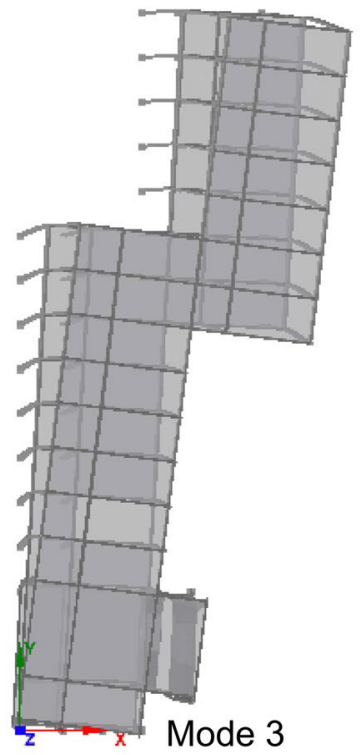

Fig. 6 Top view of the three main modal shapes of the case-study building

25,000 MPa; and (2) existing steel for smooth reinforcement, with mean yielding strength equal to $391 \mathrm{MPa}$ and an elastic modulus equal to $200,000 \mathrm{MPa}$. The material inelasticity was taken into account through the Mander et al. (1988) and Menegotto and Pinto (1973) constitutive laws for concrete and steel, respectively.

Force-based inelastic frame elements were used to model beams and columns, whilst elastic properties were assigned to the stair system. Masonry external infills were not modelled explicitly, but only considered as applied loads on perimeter beams. Rigid diaphragms were deemed suitable to represent the in-plane behaviour that is typical of this type of concrete and hollow clay blocks mixed floors. In the absence of details regarding potential perimeter walls at the small basement level (at one end of the building), and considering that in the context of this demonstrative application a precise and faithful reproduction of the characteristics of the building is not of essence, a frame structural configuration was assumed throughout the full height of the building. The total weight of the building, excluding foundations, was estimated to be equal to around 1250 tons.

An eigenvalue analysis was performed to identify the dynamic properties of the casestudy. The first modes in each of the three main directions of vibration $\left(\mathrm{X}, \mathrm{Y}, \mathrm{R}_{\mathrm{z}}\right)$ are described in Table 1, and the modal shapes are represented in Fig. 6. The first mode is 

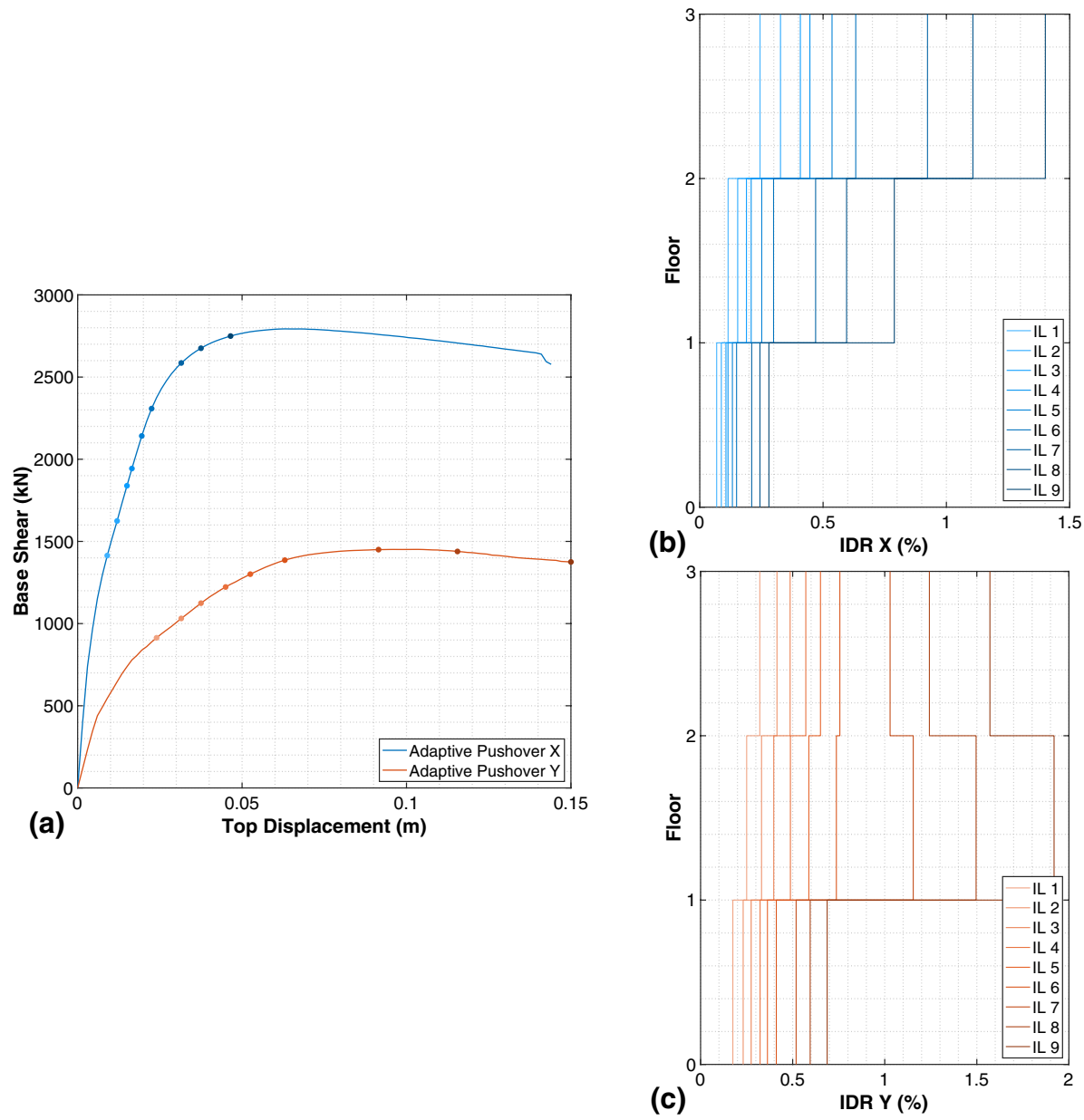

Fig. 7 Capacity curves (a) and IDR profiles in $\mathrm{X}(\mathbf{b})$ and $\mathrm{Y}$ (c) directions of the school building for nine Intensity Levels-ILs (30, 50, 72, 101, 140, 201, 475, 975, 2475-year return periods)

translational in the longest direction Y, which, due to the previously discussed columns' orientation, is the more flexible of the two directions. The second mode is torsional, albeit with a $38.5 \%$ mass contribution on the translation along X. Lastly, the third mode is primarily translational in X. The cumulative mass percentage of these three main modes is approximately equal to $90 \%$ of the total mass of the building.

Displacement-based adaptive pushover analyses (Antoniou and Pinho 2004) were performed in the two main directions (Fig. 7). Verification checks for brittle (shear in beams, columns, and non-confined beam-column joints) and ductile (chord rotation in beams and columns) mechanisms were carried out according to the NTC-18 (MIT 2018) prescriptions. Interstorey Drift Ratio (IDR) profiles for nine seismic Intensity Levels (ILs) corresponding to return periods ranging from 30 to 2475 years (Fig. 7), needed for the seismic loss assessment according to the FEMA P-58 approach (Sect. 3.1.2), were predicted from the capacity curves through the N2 method (Fajfar 2000). 


\section{Earthquake loss and energy consumption estimation for the as-built structure}

\subsection{Economic loss assessment}

The Italian Seismic Risk Classification (MIT 2017) was introduced with the main objective of facilitating and stimulating the much need of seismic upgrading of the majority of the building stock in the country, which, by virtue of its old age, is typically characterised by insufficient earthquake resistance (e.g. Crowley et al. 2009; GEM 2018; DPC 2018). As such, articulated procedures such as estimation of average annual losses are replaced with simpler seismic code-based workflows, discussed and described in detail in Cosenza et al. (2018), with a view to provide practitioners with practical approaches for seismic loss estimation pre- and post-retrofit, so that seismic class upgrades due to seismic strengthening interventions may then be used to gain access to tax deductions or other financial incentives, e.g. the so-called "Sismabonus" (PCM 2016), that will hopefully encourage seismic retrofitting of existing buildings. In other words, therefore, economic loss values obtained from the procedures included in the Italian Guidelines for Seismic Risk Classification are typically interpreted to have more of a relative, rather than absolute significance. Nonetheless, given the Italian context of the case-study considered in this work, these Guidelines will be used to obtain a first estimate of economic losses, a value that will then be superseded with that obtained using a more elaborate and fit-for-purpose alternative, the procedure for seismic loss estimation developed within the framework of the FEMA P-58 project series (ATC 2018a, b), adopted in this study through the employment of the PACT tool (ATC 2018c).

\subsubsection{Loss estimation using the Italian Guidelines for seismic risk classification}

The seismic risk class is assigned based on two different indices: the building safety index (referred to as SI-LS index), estimated at the Life-Safety Limit State (LSLS), and the Average Annual Loss (referred to as AAL, or PAM, in Italian). The former index is defined as the ratio between the capacity and the demand Peak Ground Acceleration $\left(\mathrm{PGA}_{\mathrm{C}}\right.$ and $\mathrm{PGA}_{\mathrm{D}}$, respectively). $\mathrm{PGA}_{\mathrm{C}}$ indicates the ground motion intensity corresponding to the building attainment of the LSLS, typically due to brittle or ductile mechanisms in structural members. Instead, $\mathrm{PGA}_{\mathrm{D}}$ is the design PGA at the building site according to the national seismic hazard map or a site-specific hazard analysis. On the other hand, the AAL (or PAM) is calculated as the area underneath the loss curve, representing all the possible losses (in terms of percentages of the building reconstruction cost) due to earthquakes with different intensity levels and thus corresponding to different limit states.

The procedure requires a nonlinear static analysis, and the assessment of four limit states, i.e. Operational (OLS), Damage Limitation (DLLS), Life Safety (LSLS), and Collapse (CLS), ranging from light to extensive building damage. Two other Limit States are conventionally included, i.e. the Initial Damage (IDLS) and total loss or "Reconstruction" (RLS) Limit States, accounting for weak and frequent seismic events that produce slight damage to buildings and for strong and rare seismic events that may cause buildings collapse, respectively. Fixed repair costs as percentages of the building Reconstruction Cost $(\mathrm{ReC})$ are assigned to each limit state; the calibration of such cost estimates was based on actual repair costs sustained after L'Aquila 2009 earthquake in buildings affected by 
Table 2 Building Life-Safety Index (SI-LS) and Average Annual Loss (AAL) classes, according to the Italian Guidelines for Seismic Risk Classification (MIT 2017)

\begin{tabular}{llll}
\hline SI-LS & Class $_{\text {SI-LS }}$ & AAL & Class $_{\text {AAL }}$ \\
\hline $100 \% \leq$ SI-LS & $\mathrm{A}^{+}{ }_{\text {SI-LS }}$ & AAL $\leq 0.50 \%$ & $\mathrm{~A}^{+}{ }_{\text {AAL }}$ \\
$80 \% \leq$ SI-LS $<100 \%$ & $\mathrm{~A}_{\text {SI-LS }}$ & $0.50 \%<\mathrm{AAL} \leq 1.0 \%$ & $\mathrm{~A}_{\mathrm{AAL}}$ \\
$60 \% \leq$ SI-LS $<80 \%$ & $\mathrm{~B}_{\text {SI-LS }}$ & $1.0 \%<\mathrm{AAL} \leq 1.5 \%$ & $\mathrm{~B}_{\mathrm{AAL}}$ \\
$45 \% \leq$ SI-LS $<60 \%$ & $\mathrm{C}_{\text {SI-LS }}$ & $1.5 \%<\mathrm{AAL} \leq 2.5 \%$ & $\mathrm{C}_{\mathrm{AAL}}$ \\
$30 \% \leq$ SI-LS $<45 \%$ & $\mathrm{D}_{\text {SI-LS }}$ & $2.5 \%<\mathrm{AAL} \leq 3.5 \%$ & $\mathrm{D}_{\mathrm{AAL}}$ \\
$15 \% \leq$ SI-LS $<30 \%$ & $\mathrm{E}_{\text {SI-LS }}$ & $3.5 \%<\mathrm{AAL} \leq 4.5 \%$ & $\mathrm{E}_{\mathrm{AAL}}$ \\
SI-LS $\leq 15 \%$ & $\mathrm{~F}_{\text {SI-LS }}$ & $4.5 \%<\mathrm{AAL} \leq 7.5 \%$ & $\mathrm{~F}_{\mathrm{AAL}}$ \\
& & $7.5 \% \leq \mathrm{AAL}$ & $\mathrm{G}_{\mathrm{AAL}}$ \\
\hline
\end{tabular}

different damage levels (Cosenza et al. 2018). As an example, a $0 \% \mathrm{ReC}$ is assigned for repair activity in the IDLS, whilst a $100 \% \mathrm{ReC}$ is assumed for the attainment of the RLS, i.e. in case of maximum damage and economic loss. Intermediate ratios are instead considered for the other limit states. Once the building performance at each limit state is assessed in terms of ground motion intensity (i.e. PGA), the corresponding frequency of exceedance $\lambda$ (i.e. the inverse of the return period) can be determined, and then integrated with the expected $\mathrm{ReC}$ ratios assigned to each limit state in order to calculate the AAL. Two letterbased rankings are then assigned to the building, one based on the life safety index and the other based on the average annual loss, according to values and classes listed in Table 2. The final seismic risk class that is assigned to the building is the lowest of the two SI-LS and AAL classes.

For the specific application discussed herein, it was assumed that the LSLS is reached when half of the elements (beams, columns, or non-confined joints) belonging to the same floor level is not verified under ductile or brittle mechanisms checks; in the as-built configuration, the mechanism that governs the LSLS is the beam-column joint shear failure, which is attained in both directions at the very first steps of the nonlinear static analysis, hence if a more conservative LS-reaching condition would have been

Fig. 8 Loss curve obtained from the application of the Italian Seismic Risk Classification approach in the as-built configuration, including the contributions of each Limit State (IDLS: Initial Damage; OLS: Operational; DLLS: Damage Limitation; LSLS: Life Safety; C: Collapse; RLS: Reconstruction)

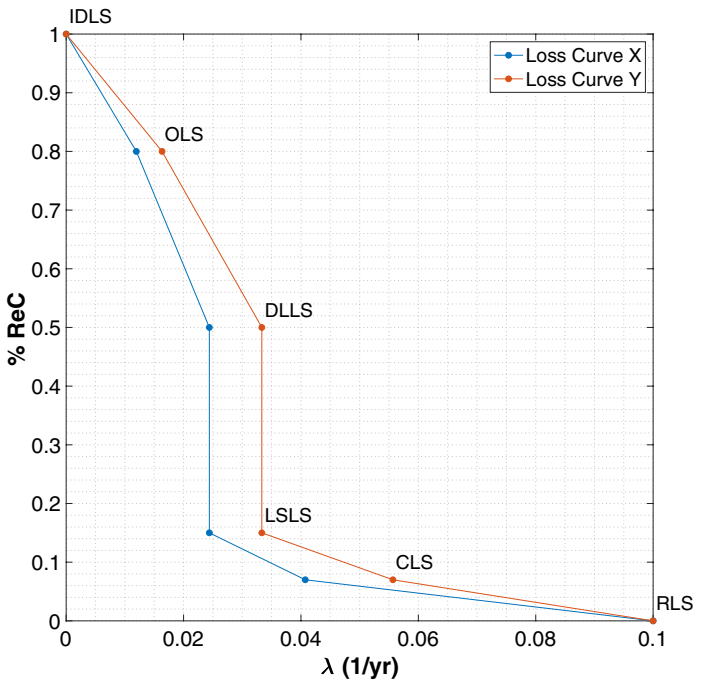


used, the ensuing seismic capacity of the building would have resulted unrealistically low. The capacity PGA was estimated to be equal to $0.09 \mathrm{~g}$ and $0.08 \mathrm{~g}$ in $\mathrm{X}$ and $\mathrm{Y}$ direction, respectively, while the demand PGA is equal to $0.30 \mathrm{~g}$.

The SI-LS index was thus calculated as the ratio between the capacity and the demand PGAs, considering the most unfavourable PGA $_{C}$ in Y direction, and it is equal to approximately $27 \%$, leading to a SI-LS class E. The AAL, on the other hand, was computed as the area underneath the loss curve, as a function of $\lambda$ and $\mathrm{ReC}$ ratios corresponding to each limit state. The loss curves obtained for the two principal directions are shown in Fig. 8, resulting in AAL ratios equal to $2.64 \%$ and $3.14 \%$ in $\mathrm{X}$ and $\mathrm{Y}$ direction, respectively. The most unfavourable AAL, i.e. 3.14\% in the Y direction, was taken to assign an AAL class D. The seismic risk class of the case-study in the as-built configuration, being the lowest between the SI-LS and AAL classes, is thus E.

Unsurprisingly, considering the previously discussed focus of the Italian Guidelines on obtaining relative seismic risk classification, rather than absolute loss estimation values, the obtained AAL estimate is conspicuously high when compared with the results obtained by DPC (2018), GEM (2018) or EFEHR (2021), all of which give AAL estimates (for the Italian territory, in general, and the Abruzzo region, in particular) that are more than an order of magnitude lower (0.06 to $0.12 \%)$. Therefore, in proceeding with the case-study application, the loss estimates computed in the section below, using the FEMA P-58 procedure, will be adopted instead.

\subsubsection{Loss estimation using the FEMA P-58 approach}

The procedure consists of four main steps: seismic hazard quantification at the site of interest, evaluation of structural performance under seismic loads, estimation of damage level in building components, and calculation of losses due to repair of damaged components. The results of the procedure are in terms of annual frequency of exceedance of different values of a Decision Variable (DV), e.g. monetary losses or environmental impacts. In this section, the procedure to perform a risk analysis of the case-study building in the as-built configuration, through the PACT tool (ATC 2018c), is discussed in some detail.

3.1.2.1 Building general information The replacement cost of the building (i.e. its cost of reconstruction of structural and non-structural components, excluding the contents of the building), referred to as $\mathrm{ReC}$, was first estimated, so as to include the potential contribution of building collapse in the estimation of average losses due to earthquakes. Although other works do use different values for the average cost of construction (e.g. a reconstruction cost of $1350 € / \mathrm{m}^{2}$ was used in the Italian National Risk Assessment (DPC 2018)), an average cost per square meter equal to approximately $900 € / \mathrm{m}^{2}$ (which includes $44 € / \mathrm{m}^{3}$ for demolition and disposal) was herein assumed, as indicated in Cardone and Perrone (2017), whose results were also taken as a reference for the repair cost consequence functions detailed in the following section. The total $\mathrm{ReC}$ was thus estimated to be equal to $€ 1.25$ million, whilst a total loss threshold value equal to 0.6 was assumed as the percentage of $\mathrm{ReC}$ for which demolition would be preferable to repair.

3.1.2.2 Inventory of damageable components The building performance model was created through an inventory of damageable components, i.e. a collection of data regarding all the components within the building that may experience damage during an earthquake. The definition of the most suitable fragility and consequence functions for each vulnerable 
component and the quantification of components of the same type at each floor are essential steps. Component-based fragility functions are distributions indicating the conditional probability of a Damage State (DS) in a component being reached given a certain value of seismic demand, in terms of an Engineering Demand Parameter (EDP), typically Interstorey Drift Ratio (IDR) or Peak Floor Acceleration (PFA). Those DSs are then translated into potential repair or replacement costs, repair time, casualties or environmental impacts by means of the so-called consequence functions, i.e. distributions indicating the conditional probability of incurring a certain loss, given the attainment of a certain DS. The PACT software already includes a library of fragility and consequence functions for different building components, but these are mainly suitable for United States (US) buildings and not fully appropriate for construction in other countries. For this reason, the fragility and repair cost functions for RC structural components and masonry non-structural elements developed by Cardone (2016) and Cardone and Perrone (2015) were used for the case-study under scrutiny, since they are suitable for Italian and European RC frame buildings built before 1970 . Therefore, the vulnerable components included in the inventory (Table 3) are:

- RC external beam-column joints, with beam bars anchored in the joint with end-hooks (EWJs);

- RC internal beam-column joints, with weak beams and columns flexural response (IWBs);

- RC ductile weak columns, with overlapped longitudinal reinforcement, for base columns (DWCs);

- RC brittle weak columns, for the short columns of the staircase (BWCs);

- Exterior masonry infills with and without windows, with expected out-of-plane collapse mechanism (EIWs, and $\mathrm{EIW}_{\mathrm{w}} \mathrm{s}$, respectively);

- Interior masonry partitions with and without doors (IPs, and $\mathrm{IP}_{\mathrm{d}} \mathrm{s}$, respectively);

- Windows and doors, referred to as partition-like components (PLs) (Sullivan et al. 2015), i.e. non-structural components whose damage and repair is assumed to be related to the DSs of infills or partitions in which they are inserted.

In Table 3, fragility functions are defined by a median EDP and a dispersion value; repair cost functions are instead defined in terms of a maximum cost, associated to a lower quantity of components that need to be repaired, a minimum cost, associated to an upper quantity of components, and a dispersion value, as recommended in ATC (2018b) to consider economies of scale. It is worth specifying that: (1) foundations, floor diaphragms and stairs were considered not vulnerable to seismic damage; (2) no quantity dispersion was introduced in the inventory, since quantities of components were individually quantified; and (3) components of the same type belonging to the same floor were assumed to be correlated, and thus subjected to the same DS. Further, it is also underlined that the inventory herein carried out is surely not exhaustive and further improvement can be achieved in future studies. Indeed, only drift-sensitive components were included, due to the lack of proper PFA (or PFV)-based fragility functions specific for the Italian building stock, thus neglecting components such as electrical service and distribution, ceilings and lighting, water and sanitary system, among others.

3.1.2.3 Assessment of the building structural response The structural response of the building was introduced in terms of single IDR profiles for each seismic intensity level, 


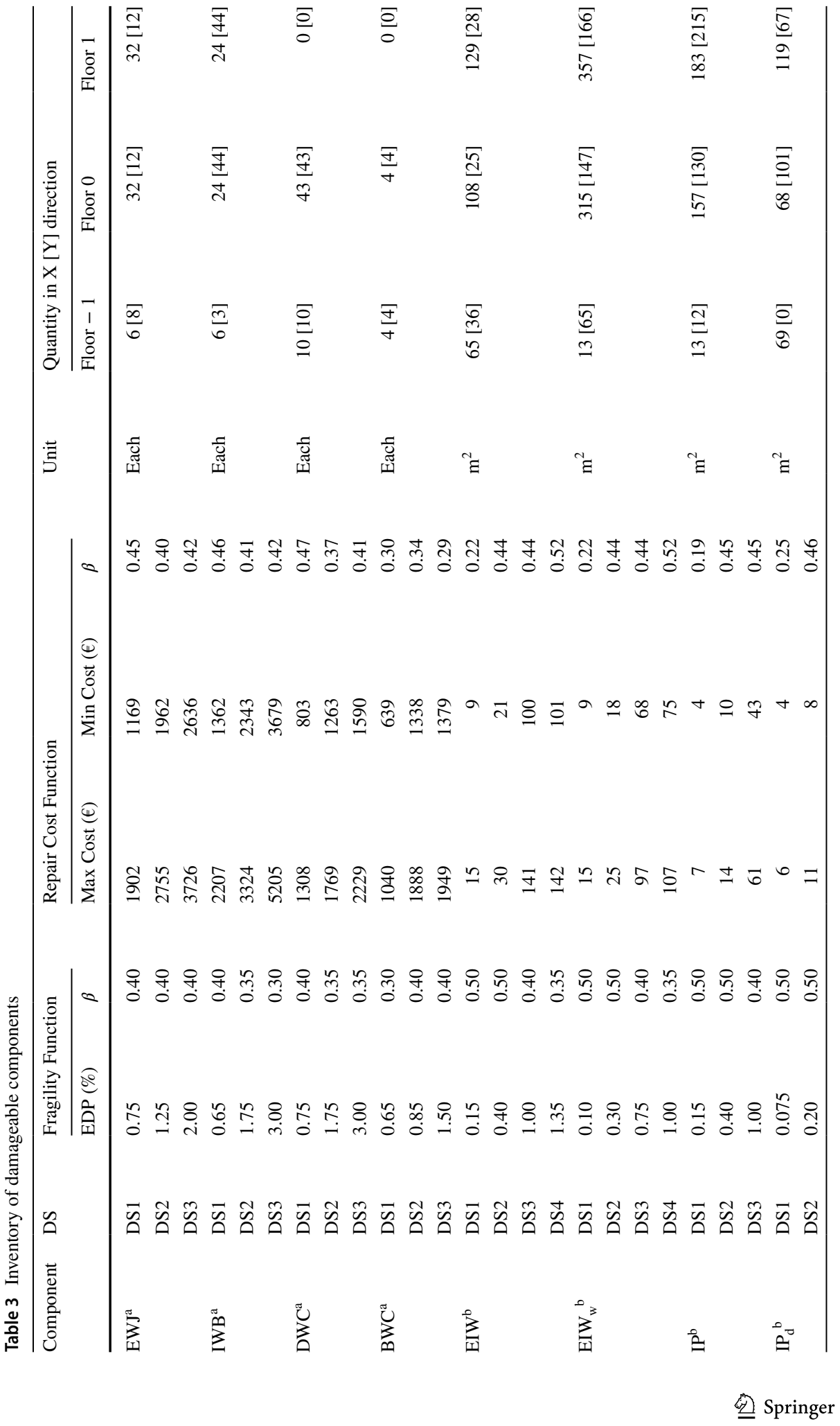




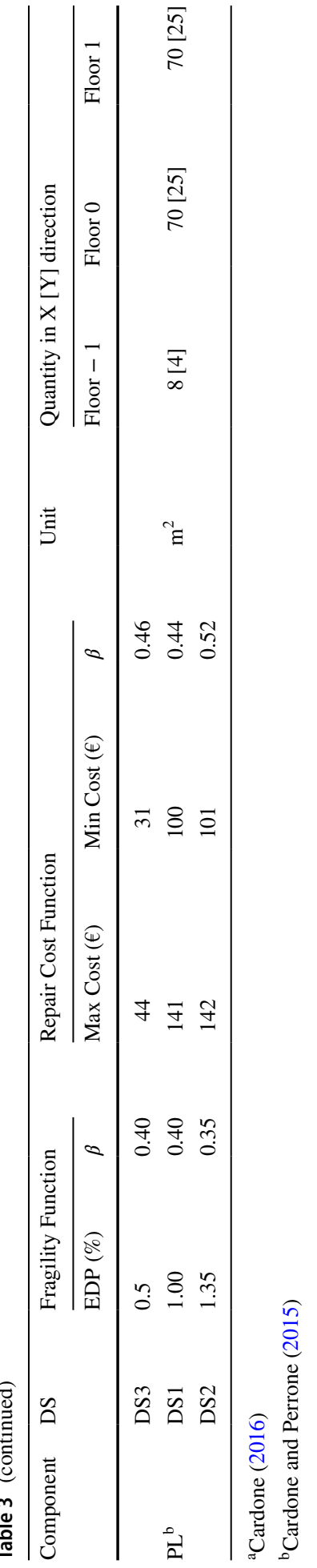


i.e. the ones plotted above in Fig. 7 resulting from nonlinear static analyses (note: further developments of the present study include ground motion records selection and nonlinear dynamic analyses, to introduce multiple IDR profiles for each IL accounting for ground motion uncertainty). In addition, the probability of incurring in partial or total collapse was assessed in the form of a collapse fragility function, which relates the probability of incurring in structural collapse to ground motion intensity, and was calculated using the SPO2FRAG tool (Baltzopoulos et al. 2017), which is a software for seismic fragility assessment based on static pushover analysis. The collapse fragility function is expressed in terms of spectral acceleration at a conditioning period $\mathrm{T}^{*}$, which was taken as the arithmetic mean of the fundamental periods in the two main directions, i.e. $0.42 \mathrm{~s}$, as suggested in ATC (2018a, b). The median collapse spectral acceleration was taken as equal to the lowest spectral acceleration at $\mathrm{T}^{*}$ corresponding to collapse obtained in the two main directions of the building, i.e. $1.03 \mathrm{~g}$ with dispersion equal to 0.68 , predicted for the weakest direction Y. Another significant parameter associated to the seismic response of the structure is the residual drift; the larger it results, the more difficult and impractical the repair of components may become due to a permanent building distortion. A lognormal distribution for the residual drift fragility function was assumed, with a median value of $1 \%$ and a dispersion of 0.3 , as suggested by Ramirez (2009). For each IL, the simplified procedure proposed in ATC (2018a, b) was thus undertaken to estimate the median residual drift ratio as a function of the median drift ratio and the median storey drift ratio at yield. The largest residual drift obtained between the two main directions was introduced in PACT, with a dispersion of 0.8 , as suggested in ATC (2018a, b).

3.1.2.4 Seismic hazard characterisation Reference to the city of Isola del Gran Sasso (Teramo, Central Italy), soil type B and topographic class T1, 50-year service life and importance class III was made to get the acceleration response spectra, according to NTC-18 (MIT 2018) prescriptions, for the nine ILs with Return Periods (RPs) ranging from 30 to 2475 years. The REASSESS software tool (Chioccarelli et al. 2019) was used to perform a Probabilistic Seismic Hazard Analysis (PSHA) and to get the hazard curve for the site of interest in terms of spectral acceleration at the conditioning period $\mathrm{T}^{*}$, to be introduced in

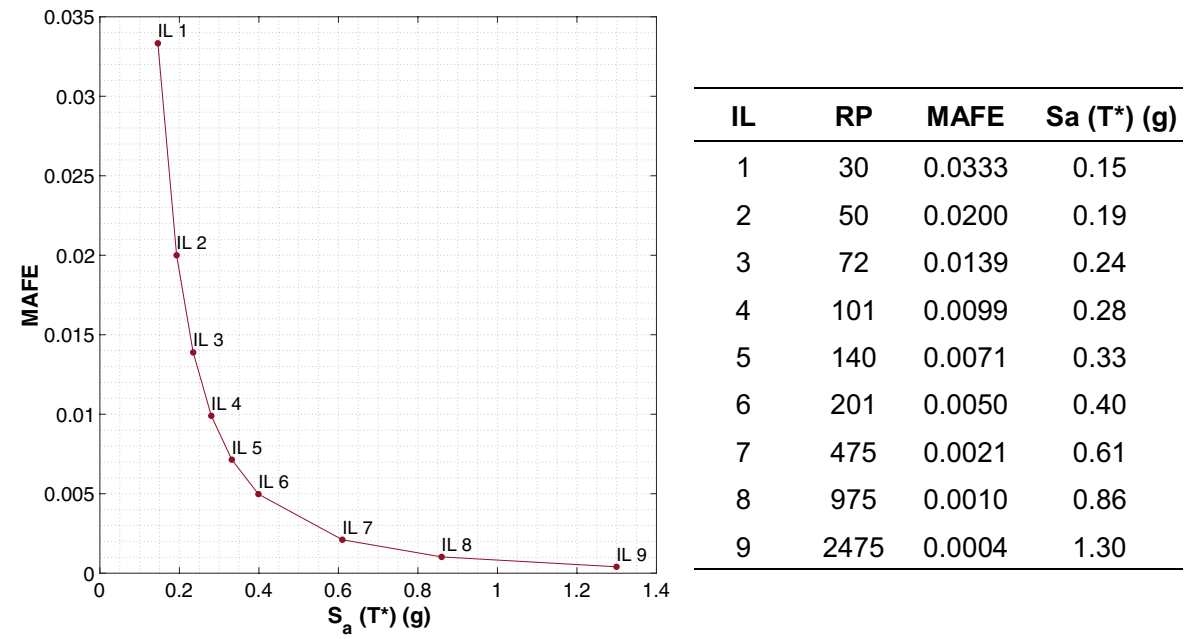

Fig. 9 Hazard curve for Isola del Gran Sasso (Teramo) for $S_{a}\left(T^{*}=0.42 \mathrm{~s}\right.$ ), from REASSESS 
Fig. 10 Loss curve in terms of repair costs obtained through PACT loss assessment

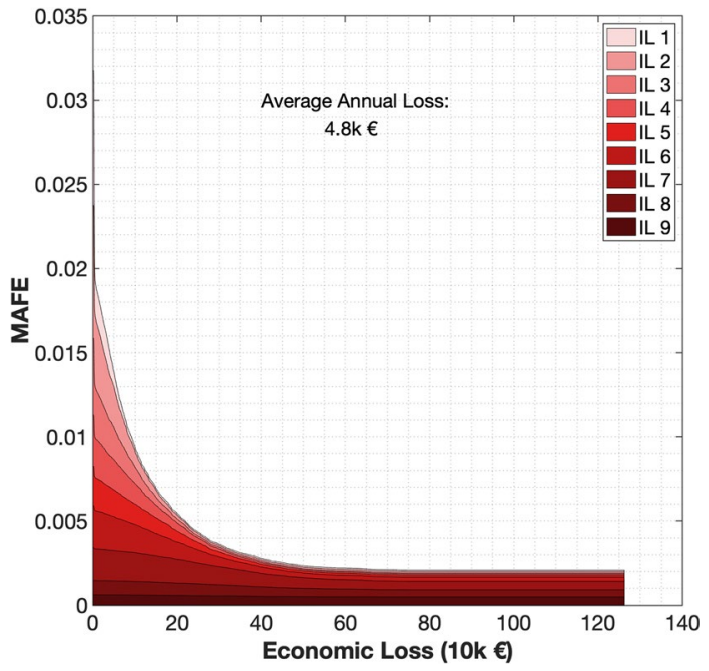

PACT. Figure 9 illustrates the hazard curve implemented in PACT, as a function of $\mathrm{Sa}\left(\mathrm{T}^{*}\right)$ and Mean Annual Frequency of Exceedance (MAFE).

3.1.2.5 Loss estimation results The results of risk assessments are typically described in terms of loss curves, which plot the total average loss as a function of the annual probability of exceedance of that loss. Economic loss analysis results for the case-study are shown in Fig. 10, disaggregated into the contributions of each intensity level. Concerning monetary losses, an AAL ratio equal to $0.38 \%$ was estimated as the fraction between the area underneath the monetary loss curve (approximately equal to $4800 €$ ) and the total replacement cost (approximately equal to $€ 1.25$ million).

The economic losses estimated herein using the FEMA P-58 procedure differ significantly from the values obtained above in Sect. 3.1.1 (not unexpectedly, for the reasons already outlined), and are instead of the same order of magnitude of the results arrived at by others (e.g. Cardone 2017; Sousa and Monteiro 2018; O'Reilly et al. 2018; O'Reilly and Sullivan 2018), who obtained AAL values ranging from 0.1 to $0.9 \%$ when assessing RC buildings in the Italian territory. Hence, in subsequent sections of this paper, the results of the FEMA P-58 approach will be considered (also because, as discussed in what follows, the latter caters for the assessment of environmental impacts as well).

\subsection{Environmental loss assessment}

The total carbon footprint due to the building construction (i.e. the carbon Impact of the building Replacement, referred to as ReI) was estimated through the Economic Input-Output (EIO) method for Life Cycle Assessment (LCA) (Leontief 1986) applied at a building level, selecting a single sector that best represents the building typology and then translating the monetary expenses in this sector into the corresponding environmental impacts. The US EIO-LCA web-tool (CMUGDI 2008; Weber et al. 2009) was used to translate sector-specific costs into environmental impacts, referring to the US 2002 Purchaser model, 
whose boundaries are from cradle to consumer. Choosing "construction" as broad sector group, and "other non-residential structures" as detailed construction sector, the TRACI impact assessment was performed to get carbon emissions for \$ $1 \mathrm{M}$ of expense in the selected sector. $615,000 \mathrm{~kg} \mathrm{eCO}$ per million dollars of expense in that sector were estimated and multiplied by the $\mathrm{ReC}$. The $\mathrm{ReC}$ was adjusted by a factor accounting for inflation between the reference year of the EIO LCA data (i.e. 2002) and the present estimate data (i.e. 2021), assumed to be equal to 1.43. The equivalent carbon emissions associated to construction were thus estimated to be approximately equal to $650,000 \mathrm{~kg} \mathrm{eCO}_{2}$. Future developments of the present study include further insights into the environmental impact assessment of buildings, e.g. through specific LCA tools, such as SimaPro (Pré Consultants 2021).

Consequence functions in terms of environmental impacts, detailed in Table 4, were developed through different damage-to-impact conversion methods. They were assumed

Table 4 Environmental impact consequence functions for each component of the inventory

\begin{tabular}{|c|c|c|c|c|}
\hline \multirow[t]{3}{*}{ Comp. } & \multirow[t]{3}{*}{ DS } & \multicolumn{3}{|c|}{ Environmental Impact Function } \\
\hline & & EIO-LCA & ICE & $\beta$ \\
\hline & & $\mathrm{eCO}_{2}\left(\mathrm{~kg} \mathrm{eCO}_{2}\right)$ & $\mathrm{eCO}_{2}(\mathrm{~kg} \mathrm{eCO})$ & \\
\hline \multirow{3}{*}{ EWJ } & DS1 & 112 & 132 & 0.40 \\
\hline & DS2 & 297 & 207 & 0.40 \\
\hline & DS3 & 529 & 280 & 0.40 \\
\hline \multirow[t]{3}{*}{ IWB } & DS1 & 129 & 109 & 0.40 \\
\hline & DS2 & 313 & 180 & 0.40 \\
\hline & DS3 & 663 & 280 & 0.40 \\
\hline \multirow[t]{3}{*}{ DWC } & DS1 & 76 & 225 & 0.40 \\
\hline & DS2 & 166 & 333 & 0.40 \\
\hline & DS3 & 285 & 420 & 0.40 \\
\hline \multirow[t]{3}{*}{ BWC } & DS1 & 61 & 140 & 0.40 \\
\hline & DS2 & 177 & 270 & 0.40 \\
\hline & DS3 & 248 & 280 & 0.40 \\
\hline \multirow[t]{4}{*}{ EIW } & DS1 & 2 & 16 & 0.40 \\
\hline & DS2 & 7 & 34 & 0.40 \\
\hline & DS3 & 44 & 162 & 0.40 \\
\hline & DS4 & 44 & 163 & 0.40 \\
\hline \multirow[t]{4}{*}{$\mathrm{EIW}_{\mathrm{w}}$} & DS1 & 2 & 22 & 0.40 \\
\hline & DS2 & 6 & 39 & 0.40 \\
\hline & DS3 & 30 & 147 & 0.40 \\
\hline & DS4 & 38 & 187 & 0.40 \\
\hline \multirow[t]{3}{*}{ IP } & DS1 & 0.6 & 5 & 0.40 \\
\hline & DS2 & 2 & 9 & 0.40 \\
\hline & DS3 & 15 & 41 & 0.40 \\
\hline \multirow[t]{3}{*}{$\mathrm{IP}_{\mathrm{d}}$} & DS1 & 0.5 & 5 & 0.40 \\
\hline & DS2 & 2 & 10 & 0.40 \\
\hline & DS3 & 12 & 41 & 0.40 \\
\hline \multirow[t]{2}{*}{ PL } & DS1 & 44 & 162 & 0.40 \\
\hline & DS2 & 44 & 163 & 0.40 \\
\hline
\end{tabular}


to be lognormally distributed, with dispersion equal to 0.4. Damage and repair activities associated to every DS of each component were converted in the corresponding equivalent carbon emissions following three alternative approaches, further described in Caruso et al. (2020a, b):

- EIO-LCA the repair activity needed for each DS was disaggregated into a list of processes to be assigned to specific industry sectors, then the cradle-to-consumer environmental impacts per dollar spent within each specific sector were extrapolated from the web-tool EIO-LCA (CMUGDI 2008, Weber et al. 2009) for the industry sectors of interest and then summed up with their own weight (i.e. the percentage indicating the contribution of a single process to the global costs of the repair activity). The inflation factor was applied herein as well, for the same reasons already discussed above regarding the initial construction of the building. Examples found in Simonen et al. (2015) and ATC (2018d) were taken as references for those calculations and to define the percentage distribution of cost allocations for the different components. For instance, for exterior masonry infills with windows, the following percentage distribution of costs was assumed for the DS at collapse: $4 \%$ adhesive, $10 \%$ clay product, $2 \%$ cleaning, $2 \%$ coating, $2 \%$ electrical, $3 \%$ glass, $10 \%$ piping, $5 \%$ plywood, $5 \%$ stucco and $3 \%$ windows. The remaining cost percentage was allocated to labour, whose contribution to environmental impact was assumed equal to zero;

- Repair description $+e \mathrm{CO}_{2}$ factors as suggested by Belleri and Marini (2016), the ICE database (Hammond and Jones 2008) was used to get cradle-to-gate $\mathrm{eCO}_{2}$ emissions per $\mathrm{kg}$ of material (e.g. concrete, glass, clay). Average embodied carbon estimates equal to $0.11,0.24,1.44 \mathrm{~kg} \mathrm{eCO}$ were selected per $\mathrm{kg}$ of concrete, clay bricks and glass, respectively. The main issue related to this approach is the need to estimate the quantity of material that needs to be replaced during the repair activity associated to specific DSs. A unit volume of material was assumed for the DS at collapse (i.e. in case of full replacement of the component), while partial volumes of material associated to intermediate DSs were scaled down proportionally to DS-specific repair costs to finally assign the $\mathrm{eCO}_{2}$ at each DS. The unit volumes were assigned according to the authors judgment, or considering available design data (e.g. for masonry infills an average area of $15 \mathrm{~m}^{2}$ and a thickness of $0.4 \mathrm{~m}$ were assumed);

- Repair-cost ratio: given that the environmental AAL ratio (from now on referred to as Average Annual Emission -AAE- ratio) is the ratio between the mean value of the impact exceedance curve and the building ReI, the environmental impacts due to repair activities were calculated by multiplying the AAL ratio in terms of monetary losses and the replacement value in terms of environmental impacts. Significant assumptions in this approach are the hypothesis of a uniform distribution of labour and material costs from initial construction to repair stages, and the inclusion of labour costs, whose cost contribution should be excluded from the calculation of environmental impacts. However, since the estimation of the monetary AAL is needed herein, this procedure was performed after running the loss analysis on PACT.

The loss curve in terms of equivalent carbon emissions, resulting from the application of the damage-to-impact conversion through the ICE database is presented in Fig. 11, disaggregated into the contributions of each intensity level. An AAE ratio equal to $0.28 \%$ was obtained, as the fraction between the area underneath the impact loss curve (approximately equal to $1.8 \mathrm{teCO}_{2}$ ) and the total replacement impact (approximately equal to 650 
Fig. 11 Loss curve in terms of carbon emissions obtained through PACT loss assessment
Table 5 Equivalent carbon emission estimates resulting from the three Damage-to-Impact conversion methods

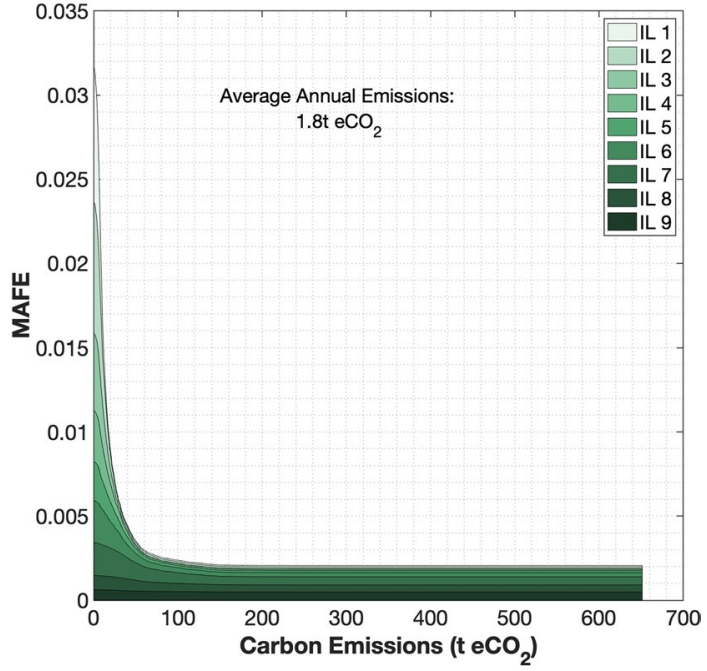

\begin{tabular}{lll}
\hline $\begin{array}{l}\text { Damage-to-Impact } \\
\text { conversion }\end{array}$ & $\begin{array}{l}\mathrm{AAE} \\
(\mathrm{kg} \mathrm{eCO} / \text { year })\end{array}$ & $\begin{array}{l}\mathrm{AAE} \\
(\% \mathrm{ReI})\end{array}$ \\
\hline EIO-LCA & 1586 & 0.24 \\
Descr. + ICE & 1819 & 0.28 \\
Repair-cost ratio & 1970 & 0.30 \\
\hline
\end{tabular}

$\mathrm{t} \mathrm{eCO}_{2}$ ). In addition, the average annual carbon emissions obtained by applying all three different damage-to-impact conversion methods described above are shown in Table 5, also expressed as a percentage of the building replacement impact. As already stated, labour does not contribute to environmental impacts and its contribution was assumed equal to the $20 \%$ of global repair costs. Thus, the impacts due to post-earthquake repairs arising from the repair-cost ratio approach were recalculated as the $80 \%$ of the $\mathrm{eCO}_{2}$ resulting from the approach (i.e. equal to around $2.5 \mathrm{t} \mathrm{eCO}_{2}$ ). It is worth reminding, however, that the cost percentage assigned to labour may vary significantly depending on the activity of interest.

Notably, as already discussed in Caruso et al. (2020b), the three damage-to-impact conversion methods led to very similar estimates of carbon emissions, demonstrating an already relatively satisfactory robustness of the three different approaches despite their very diverse assumptions and required information. However, it is worth emphasising the lack of comprehensive inventories from where to collect information on environmental impacts of specific components or activities. Furthermore, available databases are often not updated to current market prices, thus adjustment factors are needed to adapt the estimates to the present material or activity prices specific for the site of interest, increasing the uncertainty of the results. The outcomes resulting from the repair description and $\mathrm{eCO}_{2}$ estimates through the ICE database were deemed the most suitable for the specific application presented herein, due to the higher uncertainties related to the other two conversion methods; the EIO-LCA method refers to a web-tool that is based on US industry data, whilst the Repair-cost ratio is based on the arguable assumption of a uniform distribution of costs from initial construction to repair stages. 


\subsection{Energy performance assessment}

Energy performance analyses are needed to estimate the energy consumption throughout the building operational phase and the related energy annual costs and emissions. Energy calculations were performed via the EC700 software tool (Edilclima 2021), which is typically used in new building design contexts. It conforms to the UNI/TS 11300 Italian technical standard series UNI/TS 11300 (2010, 2012, 2014, 2016a, 2016b, 2019), considering all energy services, i.e. heating, cooling, domestic hot water, ventilation, lighting, energy needs of escalators and elevators, if any. The software has a climatic data archive that provides, for each Italian municipality, average data on external temperature, solar irradiation, diffused solar irradiation, external relative humidity, vapour pressure and average wind speed to be used as input for the analyses. For our scope, an analysis in static conditions was performed to estimate the energy needs for heating and electric systems of the school building in Isola del Gran Sasso and check thermal bridges and mould.

The total annual energy consumption of the building in the as-built configuration is equal to $263 \mathrm{kWh} / \mathrm{m}^{2}$ per year, of which $233 \mathrm{kWh} / \mathrm{m}^{2}$ per year are needed for the heating system and $30 \mathrm{kWh} / \mathrm{m}^{2}$ per year for the electric system. It results in $315,000 \mathrm{kWh} / \mathrm{year}$. Taking the calorific value of natural gas equal to $10.69 \mathrm{kWh} / \mathrm{Nm}^{3}$, the annual energy consumption of the building is equivalent to $30,000 \mathrm{Nm}^{3} /$ year of natural gas. Assuming a cost of approximately $1 €$ per $\mathrm{Nm}^{3}$ of natural gas, annual costs due to energy consumption are about $30,000 € /$ year $\left(21 € / \mathrm{m}^{2}\right.$ per year). Concerning carbon emissions, $54,000 \mathrm{~kg} \mathrm{eCO}_{2} /$ year are produced by natural gas (for the heating system), and $6000 \mathrm{~kg} \mathrm{eCO}_{2} /$ year are produced by electricity (for heating system, domestic hot water system and lighting), resulting in $60,000 \mathrm{~kg} \mathrm{eCO} /$ year $\left(43 \mathrm{~kg} \mathrm{eCO} / \mathrm{m}^{2}\right.$ per year). It is noted that energy consumption for heating and electric systems only is considered herein, since they represent the major contributors to total energy use, but future developments of the study will include the contribution of the cooling system as well.

According to MIT (2015), each building is assigned a specific energy class represented by an alphanumeric scale of 10 levels ranging from A4, A3, A2, A1, B, C, D, E, F to G. The A4 class is the most efficient one (corresponding to a lower energy consumption), whilst letter $\mathrm{G}$ stands for the least efficient class (corresponding to a higher energy consumption). In other words, the higher is the class, the more economic and ecologic (i.e. lower annual costs and emissions) is to keep comfortable conditions indoor. The energy class is assigned based on the global Energy Performance index of a "reference building" $\left(E P_{r e f}\right)$, i.e. a building that is identical to the study-building in terms of geometric characteristics (e.g. volumes, location and orientation, type of use, and so on) but with standardised envelope (walls, roofs, windows, doors) and equipment, as it would have been built according to the current minimum requirements. The energy class for the case-study building considered herein is class $\mathrm{E}$.

\section{Earthquake loss and energy consumption estimation for the different retrofitted configurations of the case-study building}

\subsection{Retrofitting options}

A number of potential retrofitting options were considered in this study. Purely seismic retrofitting interventions include external joints strengthening and the introduction of new 
RC shear walls (options 1 and 6 in the list below). Typical energy refurbishments consist in the introduction of an insulation layer all over the building vertical envelope, and in this specific application two different thermal coatings were investigated (options 4 and 5 in the list below). Lastly, integrated strategies couple different types of intervention aiming at the improvement of both seismic and energy performances (options 2, 3, 7, and 8 in the list below). Clearly, these solutions constitute only a small subset of all the existing retrofitting possibilities, in terms of both seismic strengthening and energy consumption reduction, however, for the purpose of the present study, they were considered as a good sample of potential interventions:

1. External Joints Strengthening ('Joint_Strength' or JS);

2. External Joints Strengthening coupled with beams and columns Coating ('BC_Coat'), referred to as 'Joint_Strength + BC_Coat' or JS + bcC;

3. External Joints Strengthening coupled with a thin Thermal Insulation ('thin_ThermInsul') layer along the building vertical envelope, referred to as 'Joint_Strength + thin_ ThermInsul' or JS + tTI;

4. Thermal Insulation ('ThermInsul' or TI) coating of the building vertical envelope;

5. Ultra-thin liquid ceramic Thermal Insulation ('ceramic_ThermInsul' or cTI) application on the building vertical envelope;

6. New RC Shear Walls ('RC_Walls' or RCW);

7. New RC Shear Walls coupled with Thermal Insulation coating of the building vertical envelope, referred to as 'RC_walls + ThermInsul' or RCW + TI;

8. New RC Shear Walls coupled with ultra-thin liquid ceramic Thermal Insulation application on the building vertical envelope, referred to as 'RC_walls + ceramic_ThermInsul' or RCW + cTI.

Existing RC buildings are often characterised by poorly detailed beam-column joints, which can give rise to brittle failure mechanisms. Their local strengthening is thus typically an effective solution to enhance the global seismic performance of a structure. In the school building considered herein, the majority of external (non-confined) beamcolumn joints did not satisfy shear capacity checks. Two alternative Steel Reinforced Polymer (SRP) solutions were thus considered for the strengthening of those joints, i.e. unidirectional sheets made of high-strength galvanized steel fibers attached to the structure through the use of either (1) a thixotropic mineral mortar; or (2) an epoxy mineral adhesive. Both solutions consist in the application of one or more layers (with thickness in the range $2-5 \mathrm{~mm}$ ) along the external joint side(s) in both horizontal and vertical directions, and along end portions (100 cm long) of adjacent beams and columns. The missing tensile stress in each beam-column joint and the number of strengthening layers needed to strengthen each joint were calculated through the capacity model developed for FRP-strengthened beam-column joints by Del Vecchio et al. (2015). The second option of joints strengthening using the epoxy mineral adhesive, due to higher strength steel fibers employed, was used for joints with higher stress demands.

As a second option, the external joints strengthening, designed as in option 1, was coupled with the coating of beams and columns along their entire length with the same thixotropic mineral mortar used for joints strengthening, with thickness in the range of 2-5 mm. It is not an option of common practice, but it was included to check whether extending the coating all along beams and columns could avoid the formation of additional thermal bridges, due to the presence of multiple materials. From a seismic 
viewpoint, this could also improve the flexural and shear performance of external beams and columns, but such contribution has not been explicitly quantified herein.

The third solution, instead, involved the coupling the external joints strengthening, designed as in option 1, with the application of a thin thermal insulation layer along the building vertical envelope. This $2 \mathrm{~cm}$ thick layer is a thermo-dehumidifying, heat cell-based insulation, made of pure natural lime, mineral binder, natural amorphous pozzolan and natural active principles. It is not a traditional thermal insulation coating, but the presence of the heat cells makes this thin layer a thermal micro-panelling system that improves the energy performance of the building.

The main advantages of thermal insulation are the limitation of a sudden change in temperature between indoor and outdoor levels, the reduction of mould and condensation, and the improvement of acoustic insulation. External insulation is typically preferred, not only because its thermal performance is better than the internal alternative, but also because it does not affect indoor space and does not need operations inside the building during the application. Thus, an external thermal coating in expanded polystyrene (or EPS) panels produced by RÖFIX (RÖFIX 2021) was proposed as a fourth retrofitting option. A thickness of $8 \mathrm{~cm}$ was calculated for the site of interest. The thickness limit is assessed through a limit of thermal transmittance (U), assigned depending on the climatic conditions and the type of wall involved. In this specific case, the site belongs to climatic zone D and the intervention only affects the vertical envelope, so U for the three-year period 2019-2021 should be at least equal to $0.29 \mathrm{~W} / \mathrm{m}^{2} \mathrm{~K}$ (MIT 2015).

An alternative solution to traditional insulating panels was investigated as a fifth option. The Bronya Facade NF (VIRC Bronya Company Group 2021) is an ultra-thin liquid ceramic thermal insulation material that can be applied in layers of thickness ranging from 1 to $2.5 \mathrm{~mm}$ (with layers of 0.5 or $1 \mathrm{~mm}$ at a time), depending on the wall material and thickness. For the case-study of interest, since it features $40 \mathrm{~cm}$ thick masonry external infills, a thickness of $2 \mathrm{~mm}$ is suggested by the producers. Since the material is applied to concrete and brick surfaces, a first cover in acrylic primer of good quality with deep penetration is also recommended. Liquid ceramic heat insulation is filled with vacuum ceramic and silicone balls, suspended in the liquid composition of synthetic rubber, acrylic polymers and inorganic pigments.

The structural strengthening techniques used today may involve individual structural members, as discussed for beam-column joints strengthening, or the entire structural

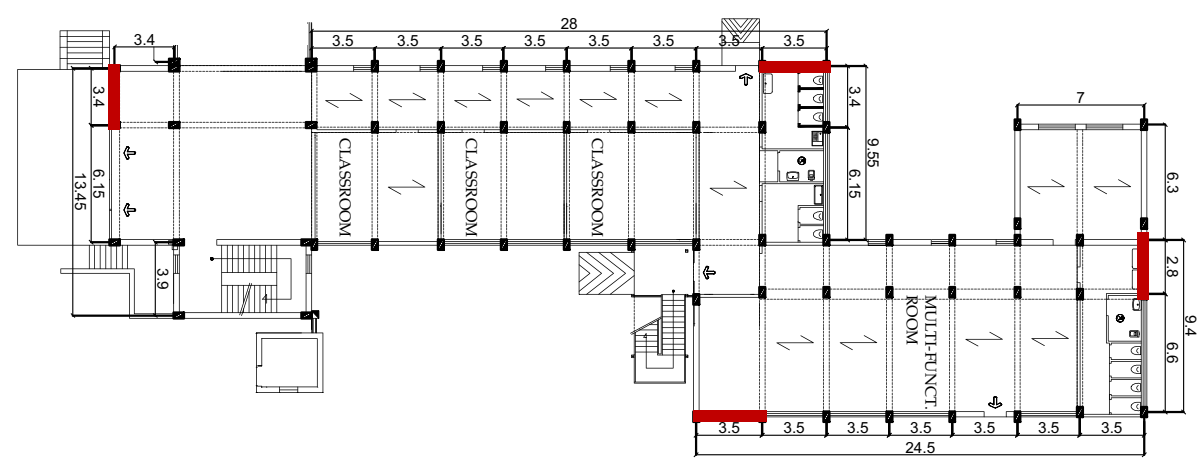

Fig. 12 Distribution in plan of the new RC shear walls 
system. In the latter case, the introduction of new structural elements modifies the dynamic behaviour of the building and usually increase global strength and stiffness of the system. Introducing new RC shear walls was thus considered as an alternative solution. For the specific case-study, four new RC shear walls were designed in order to satisfy the checks at the life-safety limit state for both flexural and shear capacity, as required by NTC-18 (MIT 2018). The new walls were placed in the two main directions, as shown in Fig. 12, to reduce torsional effects in the structure, incorporating existing RC columns and beams at each floor and carrying out seismic horizontal loads almost entirely. It is noted that the introduction of new walls implies the demolition of the existing masonry infills and the construction of new foundations also, all of which were duly considered in the cost and impact estimates due to the retrofit installation. Floor diaphragms were assumed to be rigid enough to be compatible with the introduction of the new RC walls.

The last two retrofitting options involved combinations of solutions already described above, i.e. from the seismic viewpoint, the introduction of new RC shear walls, as described for option 6, and from the energy viewpoint, the application of a thermal insulation system, either the EPS panels (option 7), or the liquid ceramic insulation (option 8).

For each retrofitting option, both installation costs and carbon emissions were estimated, using product technical datasheets, available price lists and environmental impact databases. Table 6 summarises those estimates per square meter of the building's floor area for each retrofitting option.

\subsection{Post-retrofit numerical modelling and structural analysis}

With reference to the structure's seismic response, two retrofitting options had to be modelled in SeismoStruct: (1) external joints strengthening; and (2) new RC shear walls. The external joints strengthening with SRP was modelled through rigid offsets at the end-portions of beams and columns adjacent to the joints. The new RC shear walls, on the other hand, were modelled with force-based nonlinear frame elements featuring: (1) new concrete, with a mean compressive strength equal to $25 \mathrm{MPa}$, and (2) new steel for reinforcement, with mean yielding strength equal to $450 \mathrm{MPa}$. Existing columns were thus incorporated within the new walls, and slightly enlarged (e.g. original width

Table 6 Installation costs and cradle-to-gate equivalent carbon emissions of each retrofitting option

\begin{tabular}{lll}
\hline Retrofitting option & $\begin{array}{l}\text { Costs } \\
\left(€ / \mathrm{m}^{2}\right)\end{array}$ & $\begin{array}{l}\text { Emissions } \\
\left(\mathrm{kg} \mathrm{eCO}_{2} / \mathrm{m}^{2}\right)\end{array}$ \\
\hline 'Joint_Strength' & 72 & 6 \\
'Joint_Strength+BC_Coat' & 79 & 7 \\
'Joint_Strength + thin_TermInsul' & 86 & 7 \\
'ThermInsul' & 61 & 9 \\
'ceramic_ThermInsul' & 64 & 1 \\
'RC_Walls' & 32 & 22 \\
'RC_Walls + ThermInsul' & 77 & 25 \\
'RC_Walls + ceramic_ThermInsul' & 80 & 17 \\
\hline
\end{tabular}



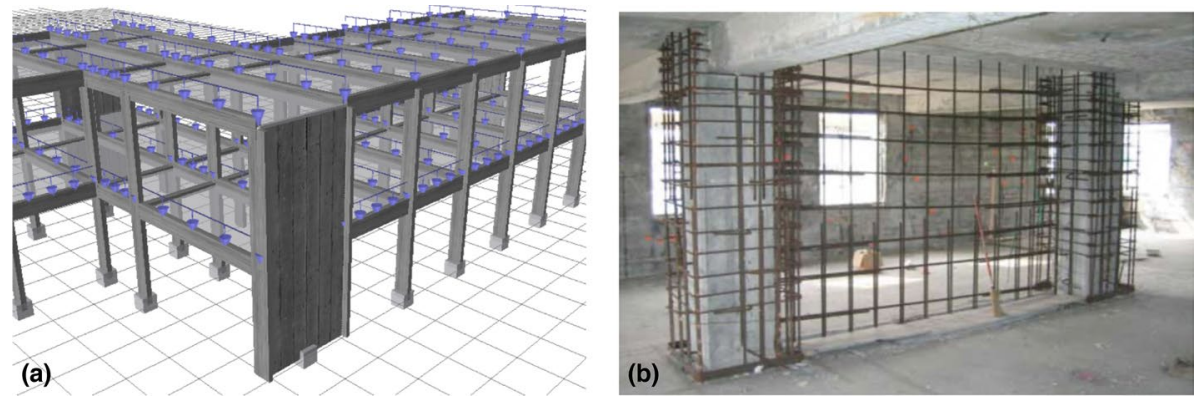

Fig. 13 Detail of the SeismoStruct model with new RC shear walls (a) and a real example (b) of the integration of existing columns into new wall (Pinho et al. 2019)

Table 7 Periods and participating masses for the two main modes of vibration of the new numerical model with RC shear walls

\begin{tabular}{llcccc}
\hline & $\mathrm{T}(\mathrm{s})$ & $\mathrm{Mx}(\%)$ & $\mathrm{My}(\%)$ & $\mathrm{Rz}(\%)$ & Type \\
\hline Mode 1 & 0.22 & 73.10 & 0.19 & 4.33 & Transl. X \\
Mode 2 & 0.16 & 0.09 & 55.60 & 0.17 & Transl. Y \\
\hline
\end{tabular}
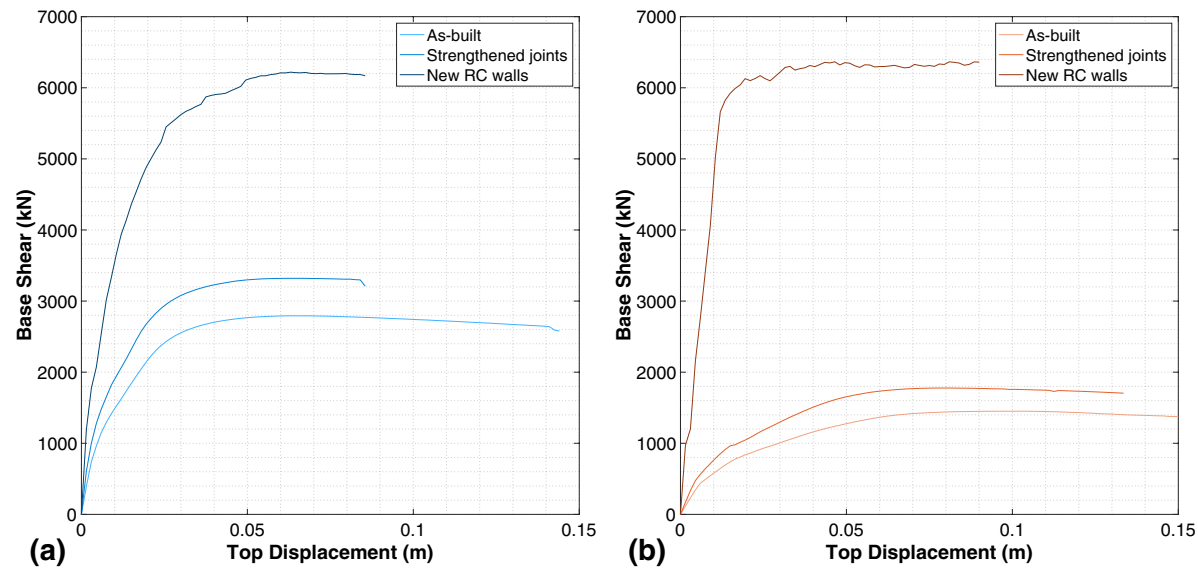

Fig. 14 Capacity curves of (1) as-built model, (2) model with strengthened external joints, (3) model with new RC shear walls, in X (a) and Y (b) directions

of $20 \mathrm{~cm}$ was enlarged to $30 \mathrm{~cm}$ ), as illustrated in Fig. 13. Through an eigenvalue analysis, it was possible to check the absence of torsional modes and a significant reduction of the periods of vibration of the translational modes in the two principal directions, as a consequence of the introduction of RC walls (Table 7, below).

Lastly, in Fig. 14, the capacity curves of the three new structural models are compared; as expected, the introduction of the new RC shear walls significantly increases 

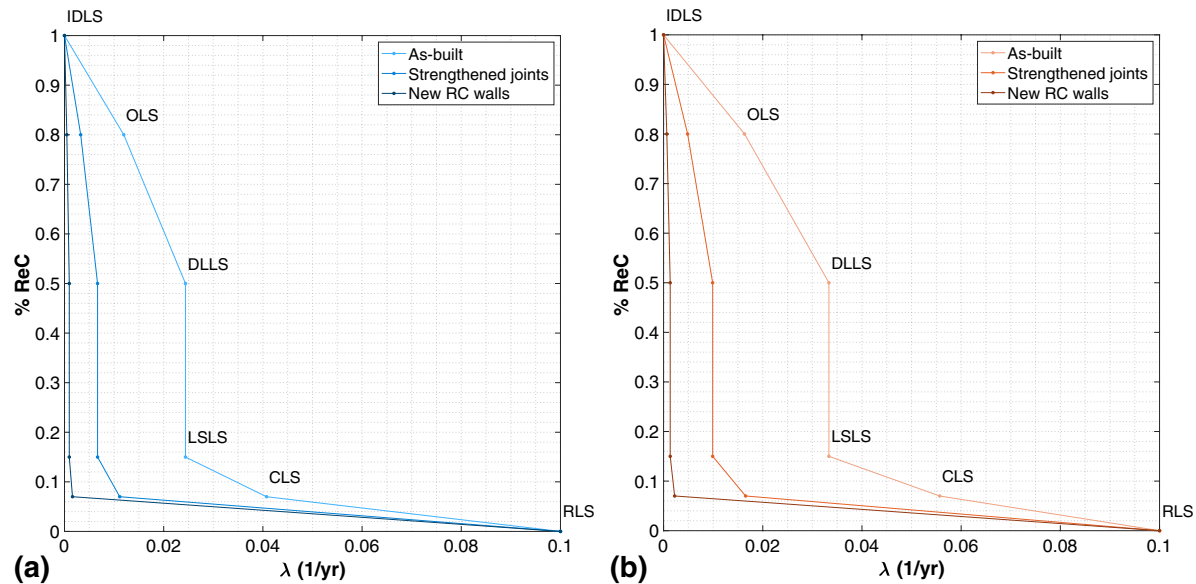

Fig. 15 Loss curves in $\mathrm{X}$ (a) and $\mathrm{Y}$ (b) directions obtained from the application of the Italian Seismic Risk Classification Guidelines, for the (1) as-built, (2) strengthened external joints, and (3) new RC shear walls configurations, including the contributions of each Limit State (IDLS: Initial Damage; OLS: Operational; DLLS: Damage Limitation; LSLS: Life Safety; C: Collapse; RLS: Reconstruction)

the capacity of the building in both directions, whilst joints strengthening introduces just a moderate increase in capacity with respect to the as-built model.

\subsection{Post-retrofit earthquake loss estimation}

\subsubsection{Loss estimation using the Italian Guidelines for seismic risk classification}

The indexes SI-LS and AAL, and the corresponding seismic risk classes were thus recalculated for the two post-retrofit structural configurations discussed above. Figure 15 illustrates the loss curves associated to the two seismic retrofitting options, together with the one for corresponding to the as-built configuration, for comparison.

Assuming that most of external joints were strengthened, the mechanism that governs the LSLS, was found to be beams shear failure in direction X. The SI-LS index is thus equal to $49 \%$ (corresponding to a SI-LS class C), whilst the AAL is equal to $1.18 \%$ (corresponding to an AAL class $\mathrm{B}$ ). The new seismic risk class for the configuration with strengthened joints is thus $\mathrm{C}$, with an upgrade of two classes with respect to the as-built option. Introducing new RC walls, instead, the mechanism that governs the LSLS, was found to be still the beam-column joint shear failure in direction Y. The SI-LS index is almost equal to $100 \%$ (corresponding to a SI-LS class A), whilst the AAL is equal to $0.46 \%$ (corresponding to an AAL class A+). The new seismic risk class for the configuration with new RC walls is thus A, thus leading to an upgrade of four classes with respect to the asbuilt option.

\subsubsection{Loss estimation using the FEMA P-58 approach}

As discussed in the previous sections, the FEMA P-58 procedure allows the estimation of both economic losses and environmental impacts, and both will thus be estimated here for 
each retrofitting option. However, to perform the PACT loss analysis in those configurations, it was necessary to make some new assumptions and modifications to the original performance model, described in Sect. 3.1.2. Indeed, fragility and consequence functions for strengthened external joints (options 1,2, and 3), exterior masonry infills (with and without windows) with insulation panels (options 4 and 7), RC walls with or without insulation panels (options 6,7 and 8) were included into the inventory of damageable members.

It was assumed that the capacity of a strengthened joint is double the capacity of its unreinforced counterpart, as proposed by the product manufacturer, based on experimental tests on an unreinforced and a reinforced external joint with SRP. The median IDRs of the original fragility functions for EWJs (listed in Table 3) were thus multiplied by a modification factor equal to 2, whilst repair cost and carbon emission functions were not adjusted (note: a similar approach to obtain fragility functions for strengthened masonry infills was already used by Cardone et al. (2019)). Strengthened external joints were thus introduced within the performance model in PACT in place of EWJs, for options 1, 2 and 3.

Thermal insulation panels in EPS were assumed to be rigidly linked to the exterior masonry infills (with or without windows). For this reason, the consequence functions in terms of repair costs and carbon emissions of EIW and EIW $_{\mathrm{w}}$ were increased to account for the presence of insulation panels, assuming that they only contribute to repair or replacement activities, without influencing the seismic performance of infills. New masonry infills with insulation panels substituted masonry infills $\left(\mathrm{EIW}\right.$ and $\left.\mathrm{EIW}_{\mathrm{w}}\right)$ in the original performance model, for options 4 and 7.

Lastly, the fragility function for RC shear wall reported by Belleri and Marini (2016) was used, for options 6,7 and 8. Maximum and minimum normalised total repair costs, as defined in Cardone (2016), of repair cost functions were assumed to be equal to those of ductile weak columns (DWCs), considering an average single-wall volume of $4.5 \mathrm{~m}^{3}$. For

Table 8 Fragility, repair cost and environmental impact functions of new damageable components

\begin{tabular}{|c|c|c|c|c|c|c|c|c|c|}
\hline \multirow[t]{2}{*}{ Component } & \multirow[t]{2}{*}{ DS } & \multicolumn{2}{|c|}{ Fragility Function } & \multicolumn{3}{|c|}{ Cost Function } & \multicolumn{3}{|c|}{$\begin{array}{l}\text { Environmental } \\
\text { Impact Function }\end{array}$} \\
\hline & & $\operatorname{EDP}(\%)$ & $\beta$ & $\begin{array}{l}\text { Max. } \\
\text { Cost }(€)\end{array}$ & $\begin{array}{l}\text { Min. } \\
\text { Cost }(€)\end{array}$ & $\beta$ & $\begin{array}{l}\mathrm{EIO} \\
(\mathrm{kg} \\
\left.\mathrm{eCO}_{2}\right)\end{array}$ & $\begin{array}{l}\mathrm{ICE} \\
(\mathrm{kg} \\
\left.\mathrm{eCO}_{2}\right)\end{array}$ & $\beta$ \\
\hline \multirow{4}{*}{$\begin{array}{l}\text { EIW + insulation } \\
\text { panels }\end{array}$} & DS1 & 0.15 & 0.50 & 17 & 11 & 0.22 & 3 & 17 & 0.4 \\
\hline & DS2 & 0.40 & 0.50 & 34 & 24 & 0.44 & 8 & 35 & 0.4 \\
\hline & DS3 & 1.00 & 0.40 & 161 & 114 & 0.44 & 52 & 165 & 0.4 \\
\hline & DS4 & 1.35 & 0.35 & 163 & 116 & 0.52 & 53 & 167 & 0.4 \\
\hline \multirow{4}{*}{$\begin{array}{l}\mathrm{EIW}_{\mathrm{w}}+\text { insulation } \\
\text { panels }\end{array}$} & DS1 & 0.10 & 0.50 & 17 & 11 & 0.22 & 3 & 22 & 0.4 \\
\hline & DS2 & 0.30 & 0.50 & 29 & 21 & 0.44 & 7 & 39 & 0.4 \\
\hline & DS3 & 0.75 & 0.40 & 110 & 78 & 0.44 & 36 & 151 & 0.4 \\
\hline & DS4 & 1.00 & 0.35 & 122 & 86 & 0.52 & 45 & 191 & 0.4 \\
\hline \multirow[t]{3}{*}{ RC walls } & DS1 & 0.84 & 0.50 & 981 & 602 & 0.47 & 57 & 675 & 0.4 \\
\hline & DS2 & 1.20 & 0.45 & 1327 & 948 & 0.37 & 124 & 998 & 0.4 \\
\hline & DS3 & 1.90 & 0.50 & 1672 & 1193 & 0.41 & 213 & 1260 & 0.4 \\
\hline \multirow{3}{*}{$\begin{array}{l}\mathrm{RC} \text { walls }+ \text { insula- } \\
\text { tion panels }\end{array}$} & DS1 & 0.84 & 0.50 & 1098 & 674 & 0.47 & 78 & 794 & 0.4 \\
\hline & DS2 & 1.20 & 0.45 & 1485 & 1061 & 0.37 & 160 & 1174 & 0.4 \\
\hline & DS3 & 1.90 & 0.50 & 1872 & 1335 & 0.41 & 265 & 1482 & 0.4 \\
\hline
\end{tabular}


Table 9 Results of PACT loss analysis in terms of both Average Annual Loss (AAL) in monetary metrics, and Average Annual Emissions (AAE) in terms of equivalent carbon emissions (using environmental impact functions calculated through the ICE database) due to seismic hazard

\begin{tabular}{lllll}
\hline Retrofitting option & $\begin{array}{l}\text { AAL } \\
(€ / \text { year })\end{array}$ & $\begin{array}{l}\text { AAL } \\
(\% \mathrm{ReC})\end{array}$ & $\begin{array}{l}\text { AAE } \\
\left(\mathrm{kg} \mathrm{eCO}_{2} / \text { year }\right)\end{array}$ & $\begin{array}{l}\text { AAE } \\
(\% \mathrm{ReI})\end{array}$ \\
\hline As-built & 4772 & 0.38 & 1819 & 0.28 \\
'Joint_Strength' & 3348 & 0.27 & 1442 & 0.22 \\
'Joint_Strength+BC_Coat' & 3348 & 0.27 & 1442 & 0.22 \\
'Joint_Strength+thin_TermInsul' & 3348 & 0.27 & 1442 & 0.22 \\
'ThermInsul' & 4798 & 0.38 & 1821 & 0.28 \\
'ceramic_ThermInsul' & 4772 & 0.38 & 1819 & 0.28 \\
'RC_Walls' & 765 & 0.06 & 430 & 0.07 \\
'RC_Walls+ThermInsul' & 788 & 0.06 & 440 & 0.07 \\
'RC_Walls + ceramic_ThermInsul' & 765 & 0.06 & 430 & 0.07 \\
\hline
\end{tabular}

option 7, the contribution of insulation panels was also added to the consequence functions of RC shear walls, as described above for masonry external infills.

Environmental impact functions for masonry infills (with and without windows) with insulation panels, and RC walls with and without insulation panels were developed using the same procedures described in Sect. 3.2 for other components. Table 8 describes fragility, repair cost and environmental impact functions for each new damageable component introduced in PACT.

The results of PACT economic and environmental loss analysis for each retrofitting option are collected in Table 9. As expected, the maximum improvement in seismic resistance is produced by the addition of new RC walls, whilst joints strengthening only leads to a slight upgrade if compared to the as-built situation. This effectively then translates into significant reduction of earthquake-induced economic losses and carbon emissions. It was also observed that the introduction of insulating panels does not produce a significant increase in average losses (due to damage to those panels).

\subsection{Post-retrofit energy performance assessment}

Energy analyses were also performed in all post-retrofit configurations, in order to quantify the contribution of each solution to the improvement of the energy performance of the building. The software EC700 was used to perform the same calculations described in Sect. 3.3 for each option.

Table 10 shows the comparison between the eight alternative retrofitting options, in terms of both annual costs and emissions due to operational energy consumption, and the corresponding energy class. Further, as discussed already in Sect. 3.3, the energy needs and corresponding carbon emissions for heating and electricity were extrapolated from the EC700 software tool, whilst annual costs due to energy consumption were calculated assuming a cost of $1 €$ per $\mathrm{Nm}^{3}$ of natural gas, as already discussed in Sect. 3.3.

It is interesting to check not only the reduction of energy consumption for heating ensued by the sole energy refurbishments, but also whether purely seismic retrofitting option could have at least a minimum effectiveness in terms of energy upgrade. For what concerns the 


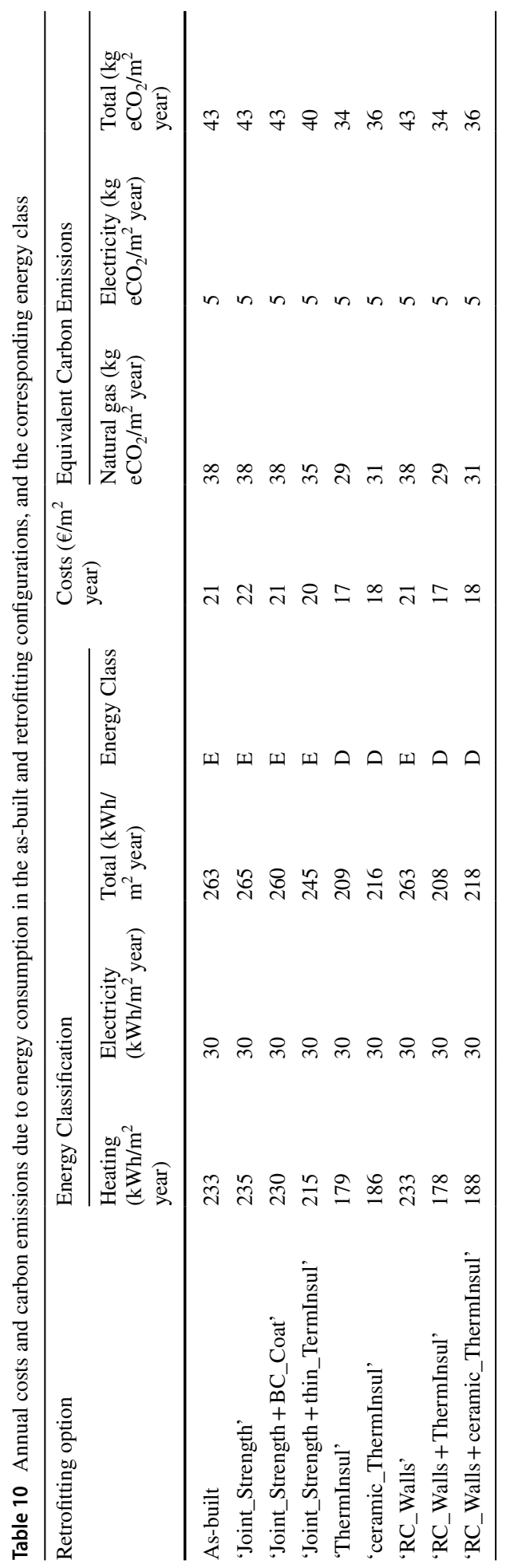


introduction of an insulation layer: (1) only a small upgrade is achieved through the thin thermal insulation layer proposed in option 3, coupled with external joints strengthening; (2) the highest effectiveness is produced by the addition of EPS panels along the vertical envelope of the building (option 4), leading to a reduction of approximately $25 \%$ of energy consumption for heating; and (3) the ultra-thin liquid ceramic thermal insulation application on the building vertical envelope (option 5) is a good alternative to EPS panels, leading to the same savings in terms of energy consumption for heating.

Concerning pure structural retrofitting options, the external joints strengthening (option 1) and the introduction of new RC shear walls (option 6) do not produce any significant variation from the as-built configuration, unless if combined with an energy refurbishment (options 3, 7 and 8). Option 2, i.e. external joints strengthening coupled with beams and columns coating, was investigated as an alternative, even if not of common practice, to check if extending the coating of option 1 all along beams and columns could avoid the formation of additional thermal bridges along external structural members, due to the presence of different materials. The results demonstrated that it actually produces only a very small improvement from the as-built option.

\section{Life cycle analysis for the as-built and retrofitted configurations of the case-study building}

\subsection{Total annual costs and emissions}

The life cycle summation proposed by Caruso et al. (2020a) and given in Eq. 1 was calculated for the as-built configuration and for each retrofitting solution, in terms of both Total Annual Costs ( $€ / \mathrm{m}^{2}$ year) and Total Annual Emissions $\left(\mathrm{kg} \mathrm{eCO} / \mathrm{m}^{2}\right.$ year), considering that:

- Construction cost and carbon emission $(C)$ were calculated as described in Sects. 3.1.2.1 and 3.2, respectively;

- $A A L_{\text {as-built }}$ and $A A L_{\text {post-retrofit }}$ are the Average Annual Losses (in terms of monetary losses or carbon emissions) due to seismic hazard, estimated through seismic loss assessment in Sects. 3.1.2 and 3.2 for the as-built configuration, and in Sect. 4.3.2 for all the retrofitting options, according to the FEMA P-58 approach;

- $E C_{\text {as-built }}$ and $E C_{\text {post-retrofit }}$ are the annual monetary expenses and carbon emissions due to the building Energy Consumption, evaluated through energy performance assessment in Sect. 3.3 for the as-built configuration, and in Sect. 4.4 for all the retrofitting configurations considered;

- Installation costs and carbon emissions of each Retrofitting Intervention $(R I)$ were detailed in Sect. 4.1;

- Demolition costs and emissions $(D)$ were estimated as roughly equal to the $20 \%$ of the corresponding estimates for construction and retrofit installation, based on the $44 € / \mathrm{m}^{3}$ estimate used for demolition and disposal, as indicated in Sect. 3.1.2.1;

- $S L_{1}, S L_{2}$ and $S L$ indicate the pre-retrofit, post-retrofit and total Service Life of the building, respectively, which were assumed to be equal to 30, 20 and 50 years, respectively;

- $F A$ is the building total Floor Area, approximately equal to $1400 \mathrm{~m}^{2}$. 


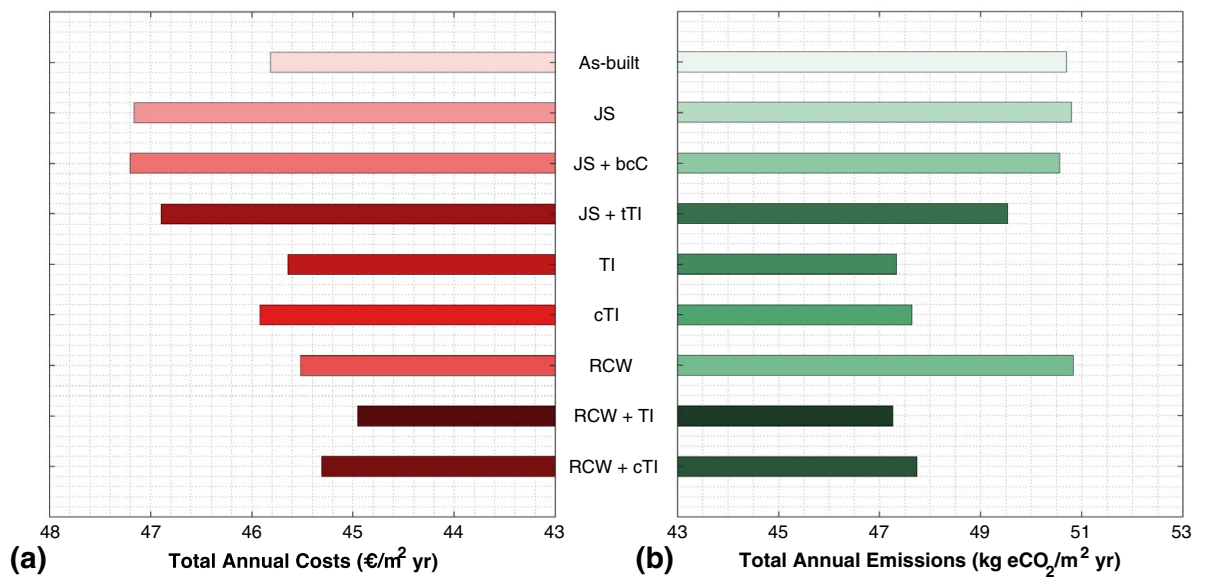

Fig. 16 Total annual costs (a) and carbon emissions (b) resulting from the life cycle summation for the as-built configuration and each retrofitting solution, assuming that the building renovation is planned after 30 years from construction. The colour gradient is assigned according to the invasiveness of each intervention

It is worth specifying that, since it is assumed that the time of assessment corresponds to the time of intervention, the cost contributions of $C, A A L_{\text {as-built }}$ and $E C_{a s-b u i l t}$ were capitalised at the present time, whilst $A A L_{\text {post-retrofit }}, E C_{\text {post-retrofit }}$ and $D$ were actualised at the present time, assuming a constant $1 \%$ value for both interest rate $\left(r_{i}\right)$ and discount rate $\left(r_{d}\right)$. In addition, it is noted that the sole energy consumption for heating was included in the following calculations, since it is responsible for the highest energy demand if compared to electricity, and because the energy refurbishments considered herein do not affect the electricity needs, as shown in Table 10.

Figure 16 illustrates total annual costs and carbon emissions resulting from the life cycle summation above for the as-built configuration and the eight retrofitting strategies considered. External joints strengthening (in options 1 and 2) does not induce significant savings neither in economic terms nor in environmental impacts. Rather, there is a small increase in terms of both total annual costs and emissions, if compared with the as-built configuration, due to the costly investment for retrofitting. Conversely, the 'Joint_Strength + thin_ ThermInsul' option, due to the presence of a thin insulation layer, performs slightly better, at least in terms of carbon emissions. Options 'ThermInsul' and 'ceramic_ThermInsul', which are sole energy refurbishments, lead to higher benefits, and EPS panels perform better than the ultra-thin ceramic thermal application. The introduction of new RC shear walls (option 6) is equivalent to the as-built configuration from the economic viewpoint, but not necessarily satisfactory in terms of carbon emissions, if compared to the other options. This result, even if new RC walls significantly improve the seismic performance of the building, is justified by the fact that in this specific application annual costs and emissions due to energy consumption for heating are much higher than those due to seismic hazard (at least of one order of magnitude), as demonstrated by the results of both seismic and energy assessments. This discrepancy may be due to the presence of large windows in the building envelope, and thus related to the specificity of this case-study used herein. Lastly, it is evident that integrated strategies (options ' $\mathrm{RC}$ _walls + ThermInsul' and ' $\mathrm{RC}$ _ walls + ceramic_ThermInsul') are the most convenient, in terms of both global costs and carbon emissions. 

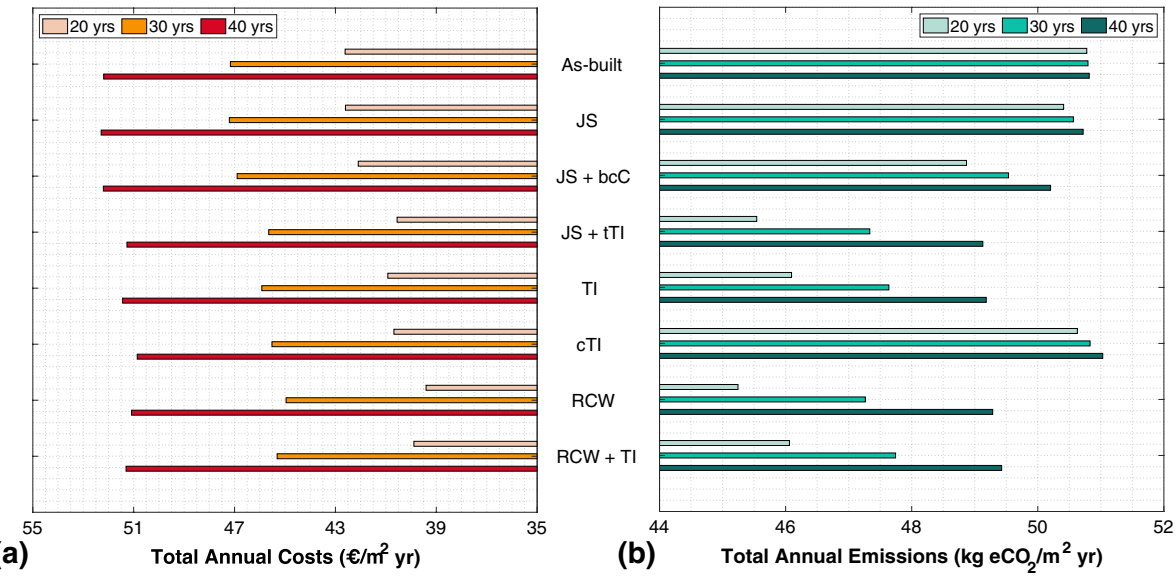

Fig. 17 Total annual costs (a) and (b) carbon emissions resulting from the life cycle summation for the eight renovation strategies considered, varying the time of intervention

Figure 17, instead, shows how the results of the life cycle summation in terms of total annual costs and emissions vary depending on the retrofitting strategy adopted and the time of intervention, as accordingly demonstrated in the illustrative example in Caruso et al. (2020a).

For each retrofitting option, the later the intervention takes place, the higher the total annual life cycle costs and emissions for each renovation strategy are. As expected, it is more convenient to plan a renovation strategy after a shorter time from construction, especially in a building that is vulnerable to earthquakes and highly energy-consuming. In addition, the higher discrepancy in the results is observed in retrofitting options with higher efficiency, as demonstrated, for instance, by coupled interventions.

Table 11 Contributions of each life cycle phase to total annual costs, for each site and retrofitting option

\begin{tabular}{|c|c|c|c|c|c|c|c|c|}
\hline \multirow[t]{2}{*}{ Retrofitting option } & \multirow{2}{*}{$\begin{array}{l}\text { Tot. } \\
€ / \mathrm{m}^{2} \text { year }\end{array}$} & \multicolumn{7}{|c|}{ Contributions to total annual costs of each life cycle phase (\%) } \\
\hline & & Constr & Eq_Pre & Enrg_Pre & Int & Eq_Post & Enrg_Post & Demol \\
\hline As-Built & 46 & 43 & 5 & 29 & 0 & 3 & 15 & 5 \\
\hline 'Joint_Strength' & 47 & 42 & 5 & 28 & 3 & 2 & 15 & 5 \\
\hline $\begin{array}{l}\text { 'Joint_Strength + BC_ } \\
\text { Coat' }\end{array}$ & 47 & 42 & 5 & 28 & 3 & 2 & 14 & 6 \\
\hline $\begin{array}{l}\text { 'Joint_Strength + thin_ } \\
\text { TermInsul' }\end{array}$ & 47 & 42 & 5 & 28 & 4 & 2 & 13 & 6 \\
\hline 'ThermInsul' & 46 & 43 & 5 & 29 & 3 & 3 & 11 & 6 \\
\hline 'ceramic_ThermInsul' & 46 & 43 & 5 & 29 & 3 & 3 & 12 & 5 \\
\hline 'RC_walls' & 46 & 43 & 5 & 30 & 1 & 0 & 15 & 6 \\
\hline 'RC_walls + ThermInsul' & 45 & 44 & 5 & 30 & 3 & 0 & 12 & 6 \\
\hline $\begin{array}{l}\text { 'RC_walls + ceramic__ } \\
\text { ThermInsul' }\end{array}$ & 45 & 43 & 5 & 30 & 4 & 0 & 12 & 6 \\
\hline
\end{tabular}


Table 12 Contributions of each life cycle phase to total annual emissions, for each site and retrofitting option

\begin{tabular}{|c|c|c|c|c|c|c|c|c|}
\hline \multirow[t]{2}{*}{ Retrofitting option } & \multirow[t]{2}{*}{$\begin{array}{l}\text { Tot. } \\
\mathrm{kg} \mathrm{eCO}_{2} / \mathrm{m}^{2} \text { year }\end{array}$} & \multicolumn{7}{|c|}{$\begin{array}{l}\text { Contributions to total annual emissions of each life cycle phase } \\
(\%)\end{array}$} \\
\hline & & Constr & Eq_Pre & Enrg_Pre & Int & Eq_Post & Enrg_Post & Demol \\
\hline As-Built & 51 & 18 & 2 & 45 & 0 & 1 & 30 & 4 \\
\hline 'Joint_Strength' & 51 & 18 & 2 & 45 & 0 & 1 & 30 & 4 \\
\hline $\begin{array}{l}\text { 'Joint_Strength + BC__ } \\
\text { Coat' }\end{array}$ & 51 & 18 & 2 & 45 & 0 & 1 & 30 & 4 \\
\hline $\begin{array}{l}\text { 'Joint_Strength + thin_ } \\
\text { TermInsul' }\end{array}$ & 50 & 19 & 2 & 46 & 0 & 1 & 28 & 4 \\
\hline 'ThermInsul' & 47 & 20 & 2 & 48 & 0 & 1 & 25 & 4 \\
\hline 'ceramic_ThermInsul' & 48 & 20 & 2 & 47 & 0 & 1 & 26 & 4 \\
\hline 'RC_walls' & 51 & 18 & 2 & 45 & 1 & 0 & 30 & 4 \\
\hline $\begin{array}{l}\text { 'RC_walls + ThermIn- } \\
\text { sul' }\end{array}$ & 47 & 20 & 2 & 48 & 1 & 0 & 25 & 4 \\
\hline $\begin{array}{l}\text { 'RC_walls + ceramic_ } \\
\text { ThermInsul' }\end{array}$ & 48 & 19 & 2 & 48 & 1 & 0 & 26 & 4 \\
\hline
\end{tabular}

The percentage contributions to total annual costs and emissions of each life cycle stage were also investigated, and are reported in Tables 11 and 12, respectively. It is recalled that each of such calculation modules refer to construction ('Constr'), earthquake-induced losses in the as-built configuration ('Eq_Pre'), operational energy needs in the as-built configuration ('Enrg_Pre'), retrofitting intervention ('Int'), earthquake-induced losses in the post-retrofit configuration ('Eq_Post'), operational energy needs in the post-retrofit configuration ('Enrg_Post'), and demolition ('Demol').

The construction phase is the major contributor to total annual costs, accounting for approximately the $40 \%$ of the total estimate, whilst it instead contributes only for the $20 \%$ of total environmental impacts. The contributions, in the as-built configuration, of earthquake losses and operational energy needs to both total annual costs and emissions demonstrate that, for this specific case-study application, running costs due to energy consumption for heating (approximately 30\%) are much higher than those due to seismic hazard (approximately 5\%). Accordingly, the major contributor to carbon emissions in the operational phase is the energy consumption for heating, that is responsible for about the $50 \%$ of total environmental impacts. The retrofitting interventions themselves do not have a contribution of any significance to the overall life cycle summation, proving that comparing alternative retrofitting options is meaningful not only in terms of one-off investments but also in terms of long-term expenses or impacts through the building post-retrofit life. Subsequently to the retrofitting intervention, it was observed that the contributions of earthquake losses and energy needs vary according to the retrofitting option adopted. Lastly, the demolition phase is responsible for approximately the $5-6 \%$ and $4 \%$ of total annual costs and emissions, respectively.

\subsection{Identification of the optimal retrofitting strategy}

Monetary expenses and environmental impacts evaluated through the post-retrofit building life, as detailed in the previous sections, can be used as performance metrics for the identification of the optimal retrofitting strategy for the building of interest. In other words, 
neglecting the contributions of construction and pre-retrofit energy needs, earthquakeinduced losses and demolition of materials used for construction (i.e. 'Constr', 'Eq_Pre', 'Enrg_Pre' and part of 'Demol' modules), which would be the same for any of the retrofitting configurations investigated, one can compare alternative renovation strategies based on costs/impacts of retrofit installation process, post-retrofit energy consumption and earthquake-induced losses, and demolition of materials used for retrofitting (i.e. 'Int', 'Eq_Post', 'Enrg_Post', and part of 'Demol' modules). The optimal retrofitting solution can be then identified as the one corresponding to the highest integrated reduction of post-retrofit costs and impacts with respect to the as-built configuration. As demonstrated in the following sections, the payback period and the average annual loss of life due to earthquakes can also be used as additional decision-making tools for the identification of the most suitable retrofitting strategy for the building under scrutiny.

\subsubsection{Payback period}

The Payback period (PB) was calculated for each retrofitting option (Fig. 18), checking when Eq. 2 (also used, for instance, by Cardone et al. (2019) for similar purposes) for the Net Present Value $(N P V)$ becomes positive, i.e. after which time interval $t$ (so-called breakeven time) the initial investment for the retrofit is fully paid back by the savings due to the retrofitting option adopted (the reader is referred to Caruso et al. (2020a) for further discussion and details):

$$
N P V=\sum_{t=1}^{S L_{2}}\left[\left(A A L_{\text {as-built }}-A A L_{\text {post-retrofit }}\right)\left(\frac{1}{1+r_{d}}\right)^{t}+\left(E C_{\text {as-built }}-E C_{\text {post-retrofit }}\right)\left(\frac{1}{1+r_{d}}\right)^{t}\right]-R I
$$

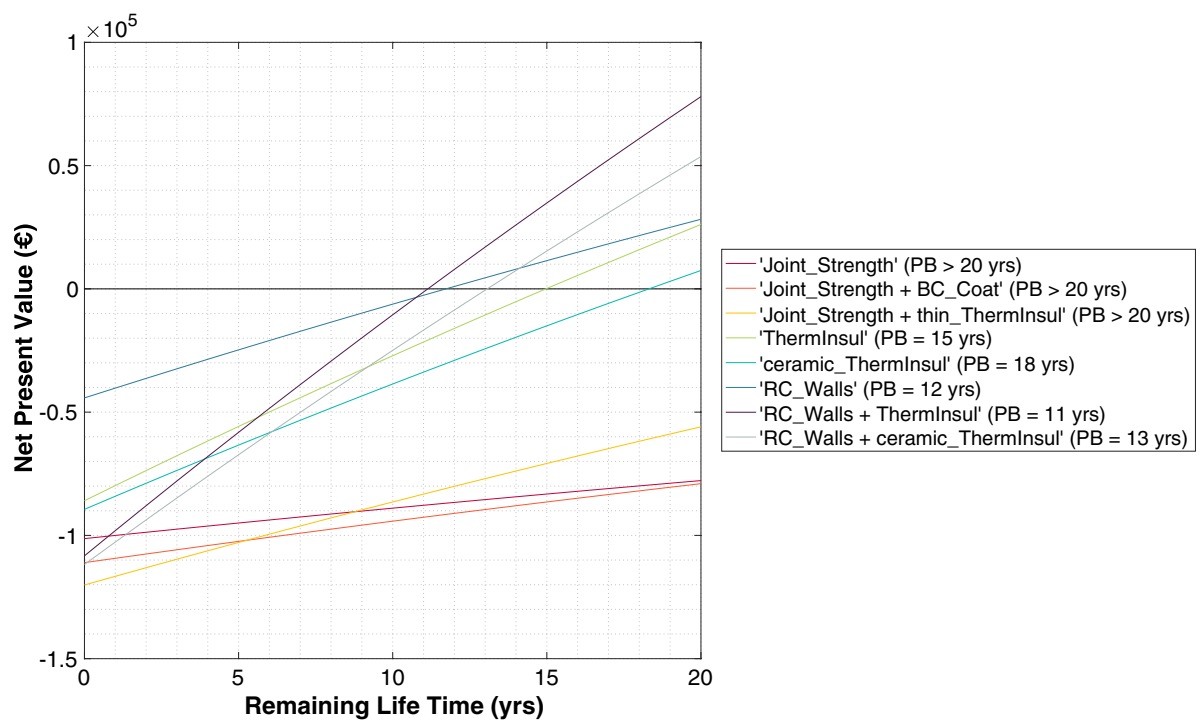

Fig. 18 Net Present Values (NPVs) and Payback periods (PBs) resulting from the cost-benefit analysis for each retrofitting option 
which includes the contributions of the retrofitting intervention itself $(R I)$, and the variations of annual costs due to earthquake losses and energy consumption ( $A A L$ and $E C$, respectively) in the post-retrofit configuration, pertinently adjusted through the discount rate $\mathrm{r}_{d}$.

Options with external joints strengthening have the longest payback periods, demonstrating that in this specific case it would be preferable to opt in favour of an energy refurbishment, or at least at a coupled intervention. Purely energy refurbishments are convenient in terms of both payback period and long-term benefits. The introduction of new RC walls has the lowest PB, due to the lowest investment cost for the retrofit. However, long-term savings of integrated renovation strategies, coupling new RC shear walls with traditional or ceramic thermal insulation, after no more than one year, are higher than those obtained with the 'RC_walls' retrofitting option alone.

\subsubsection{Average annual loss of life (AALL)}

As further discussed in Caruso et al. (2020a), the estimation of potential fatalities due to earthquake occurrence cannot be neglected in life cycle frameworks such as the one presented herein, since casualties risk does constitute a major societal concern. At this stage of the study, the sole loss of life due to earthquakes is included, neglecting injured and homeless people. A number of casualty models are available, such as the one included in the FEMA P-58 approach, the one by Coburn et al. (1992), or its adaptation to the Italian case by Zuccaro and Cacace (2011). In order to make use of the latter, however, one would need to first somehow harmonise component-specific and building-specific damage states, for which reason, in the current application the FEMA P-58 approach for the calculation of average annual fatalities was used instead (which is also in continuity with the seismic economic and environmental loss estimations carried out in Sects. 3.1.2 and 3.2).

Since most fatalities occur as a result of partial or total building collapse, the PACT Tool requires the definition of the probability of incurring structural collapse in terms of a collapse fragility function and of collapse modes (e.g. single-storey or multi-storey collapse, partial floor collapse, etc.). In addition, it is necessary to define a population model according to the building occupancy, i.e. the number of occupants that are present within the building envelope at different hours of the day, days of the week, and months of the year. Randomly generating the time of earthquake occurrence for each Monte Carlo realisation, PACT determines the number of occupants involved in collapsed areas, either dead or injured. Some of the non-structural components or building contents may cause additional deaths or injuries in the floor area adjacent to the component itself (e.g. exterior infills, interior partitions, shelves). For this reason, PACT allows the introduction of casualty consequence functions for any individual component at the damage states that is more likely to result in fatalities or injuries. Those consequence functions are defined by the area that would be affected by potential life safety hazards due to component damage and the fatality and injury rates in such area. Therefore, once the building collapse and the mode of collapse have been determined in a given realisation, the number of resulting casualties is estimated based on the number of occupants present within the building at the time of earthquake occurrence, the fraction of floor area affected by collapse, and additional component-specific casualty consequences.

For the present case-study, the collapse fragility function was already introduced in Sect. 3.1.2 as a function of ground motion shaking. Three modes of collapse (i.e. each single-storey collapse) were identified with probability of occurrence equal to $0.1,0.45$ 
Table 13 Results of PACT loss analysis in terms of Average Annual Loss of Life (AALL)

\begin{tabular}{ll}
\hline Retrofitting option & AALL (p/year) \\
\hline As-built & 0.03 \\
'Joint_Strength' & 0.02 \\
'Joint_Strength + BC_Coat' & 0.02 \\
'Joint_Strength + thin_TermInsul' & 0.02 \\
'ThermInsul' & 0.03 \\
'ceramic_ThermInsul' & 0.03 \\
'RC_Walls' & 0.01 \\
'RC_Walls + ThermInsul' & 0.01 \\
'RC_Walls + ceramic_ThermInsul' & 0.01 \\
\hline
\end{tabular}

and 0.45 for each floor, respectively, and for each of those three modes, casualty rates in the order of $90 \%$ for casualties and $10 \%$ for serious injuries are suggested in ATC (2018a, b) for RC constructions. The population model was selected amongst the ones available in the PACT tool itself, i.e. the one for secondary schools, and the peak number of occupants per $100 \mathrm{~m}^{2}$ was assumed equal to 18 . For external masonry infills with and without windows and interior partitions with and without doors at collapse, the casualty-affected area was assumed to be equal to the infill or partition unit (approximately $15 \mathrm{~m}^{2}$ ), even if the impacted area can sometimes be higher than that of the component itself, due to debris or other material release during collapse. In addition, the fatality rate in the affected area was assumed equal to $90 \%$, whilst the injury rate equal to $10 \%$, both with a dispersion of 0.5, as suggested in ATC (2018a, b).

The results in terms of AALL (persons per year) are reported in Table 13 for the as-built configuration and for the eight retrofitting solutions investigated. These fatality estimates cannot be compared with other currently available results (DPC 2018), because the latter are currently reported at regional scale without a distinction between building typology, and thus result inevitably and significantly lower (because they

Fig. 19 Post-retrofit annual costs and emissions plots, including the payback periods for each retrofitting intervention, assuming a post-retrofit life of 20 years

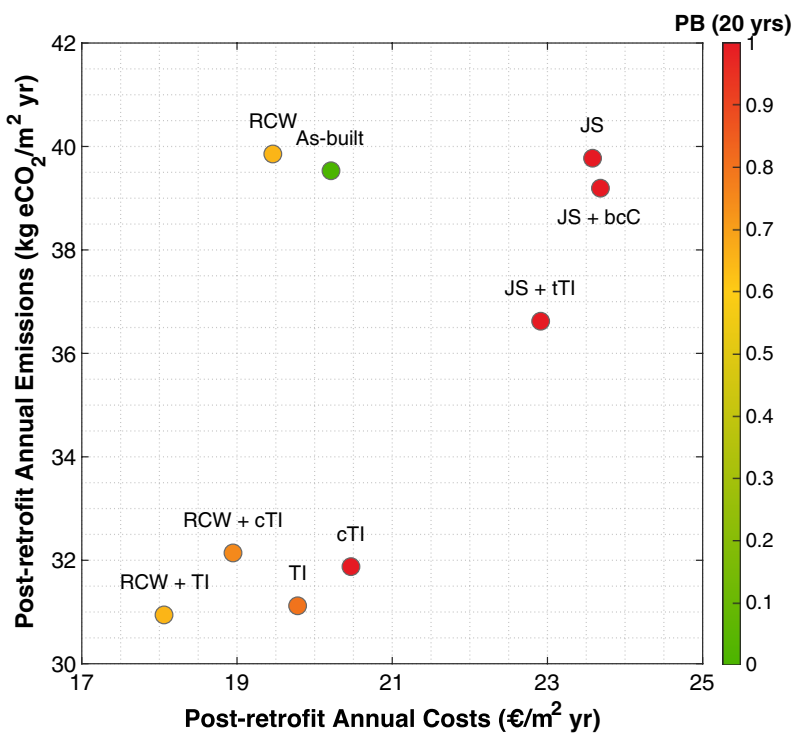


include also casualty estimates for structures that are significantly less vulnerable than that considered in this study).

\subsubsection{Performance metrics for the selection of the optimal retrofitting solution}

The results obtained from the summation through the post-retrofit life are herein plotted together, in normalised fashion, to aid the process of selecting the optimal retrofitting option for the site of interest. The payback period is normalised with respect to the assumed remaining life of the building after the retrofitting intervention (20 years, in the current application). Figure 19 compares the results for the eight retrofitting options and the as-built configuration. The colour scale provides an indication on the payback period, with green and red indicating an earlier and longer payback period, respectively. The optimal retrofitting option, considering post-retrofit annual costs and emissions as performance metrics, will be the one that results the closest to the axes origin. Hence, the integrated solution coupling the introduction of new RC shear walls and EPS insulating panels constitutes the most convenient option, in terms of both costs and carbon emissions, with the additional advantage of also featuring the shortest payback period.

Figure 19 renders also very clear how, for this specific case-study, a JS intervention alone would be wholly counterproductive, leading to an increase of both costs and emissions with respect to the as-built case, due to high installation costs and limited post-retrofit savings. The addition of beam-column coating ( $\mathrm{bcC}$ ) would reduce slightly the carbon emissions, but not really significantly. Only through the coupling of this structural intervention with a thin thermal insultation layer along the building vertical envelope (tTI) would one obtain tangible reductions in post-retrofit annual costs and emissions. On a different note, Fig. 19 shows also very clearly that, as discussed already, for this specific case-study a sole energy refurbishment such as thermal insulation (TI) leads to a non-negligible reduction of both annual costs as well as carbon emissions. This should, however, not lead one to necessarily conclude that, for this case, the introduction of $\mathrm{RC}$ walls provides relatively

Fig. 20 Post-retrofit annual costs and emissions plots, including the average loss of life for each retrofitting intervention, assuming a post-retrofit life of 20 years

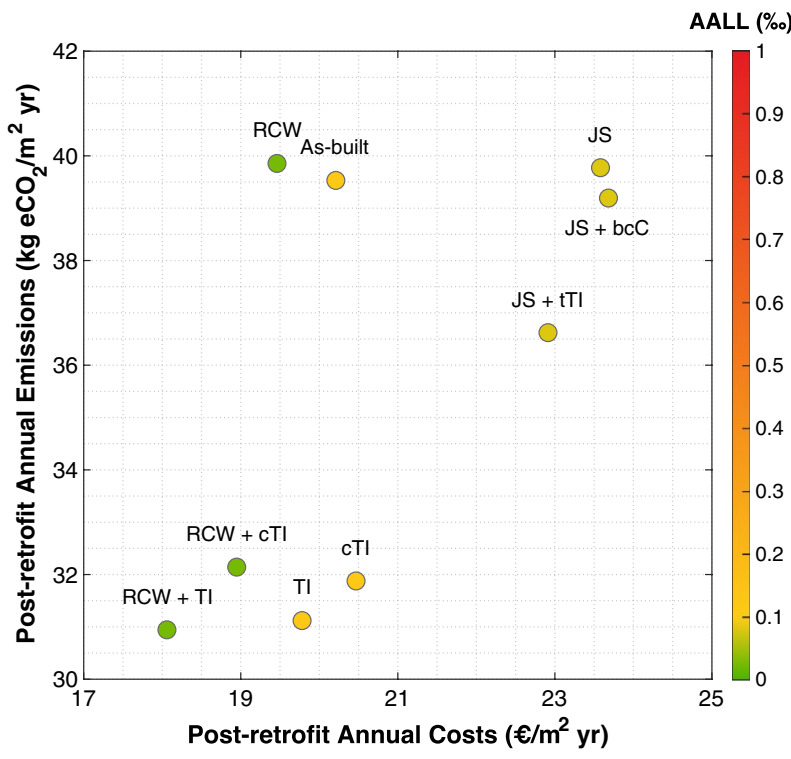


limited added-value, given that, it is recalled, the latter structural intervention will bring the non-negligible benefit of reducing the risk of loss of life, as discussed subsequently and in Sect. 5.2.2.

The AALL is instead normalised with respect to the number of building occupants, i.e. equal to approximately 250 individuals (assuming 18 people present per $100 \mathrm{~m}^{2}$, as indicated in the previous Section). Figure 20 compares the results for the eight retrofitting options and the as-built configuration. The green-to-red colour scale provides an indication on the increasing number of resulting casualties.

The optimal retrofitting solution, considering not only post-retrofit costs and emissions but also the possibility of loss of life, is still the integrated solution combing the introduction of new RC walls and EPS insulating panels. If one were to consider Fig. 19 alone, the sole energy refurbishment with EPS panels (TI) could seem very appealing, due to lower working times and invasiveness with respect to the integrated solution, and a relatively similar benefits in terms of post-retrofit costs and emissions. However, Fig. 20 renders it quite evident that disregarding the introduction of new RC walls would effectively imply that a high risk of loss of life would be maintained, something that would certainly be far from optimum, from a human and societal perspective.

Identical calculations were performed for the same building located in other two different geographic sites (though still considering the retrofitting options as designed for Isola del Gran Sasso): (1) Reggio Calabria, located in the climatic zone B with 772 Heating Degree Days (HDD), and characterised by a $0.2 \%$-annual-probability-of-exceedance PGA in the range between 0.25 and $0.275 \mathrm{~g}$; and (2) Cuneo, located in the climatic zone F with $3012 \mathrm{HDD}$, and characterised by a $0.2 \%$-annual-probability-of-exceedance PGA in the range between 0.125 and $0.15 \mathrm{~g}$. In other words, Reggio Calabria may be considered as a highly seismic site with a warm weather, whilst Cuneo may instead be deemed a cold weather location, thus with high energy needs for heating, and characterised by low seismic hazard. In comparison, the originally considered site, Isola del Gran Sasso (Teramo), can be deemed as featuring intermediate climatic and seismic conditions (i.e. climatic zone
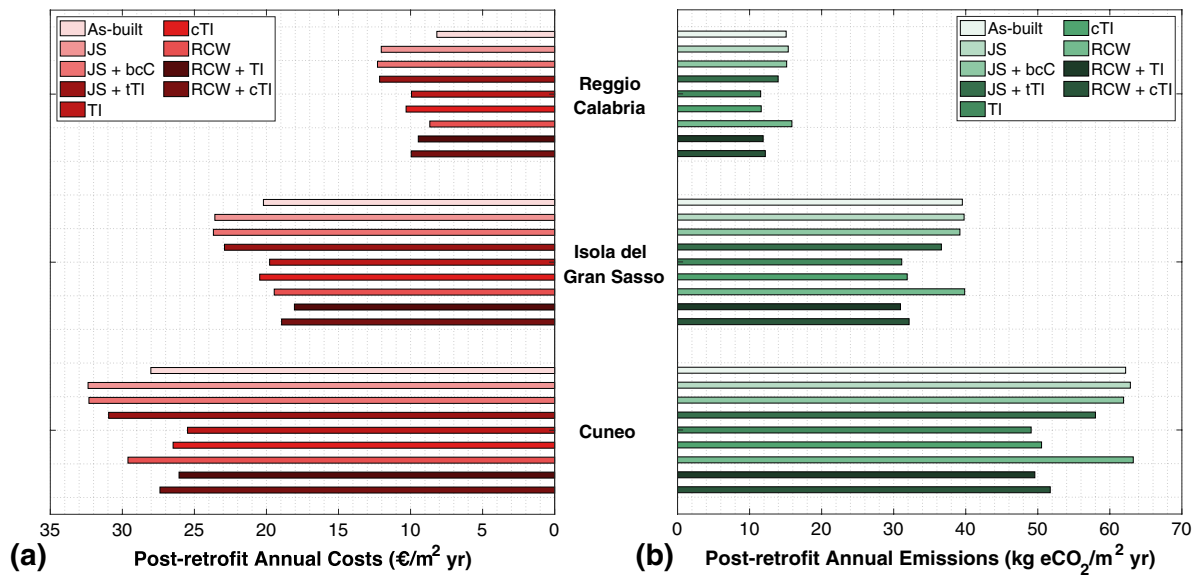

Fig. 21 Post-retrofit annual costs (a) and emissions (b) for the as-built configuration and the retrofitting options at each site, assuming a post-retrofit life of 20 years. The colour gradient is assigned according to the invasiveness of each intervention 
D with 2038 HDD, and 0.2\%-annual-probability-of-exceedance PGA between 0.175 and $0.2 \mathrm{~g}$ ). It is noted that, for this specific application, geographic locations were selected based on different HDD measures, since the sole contribution of the heating system was included in the summation, for reasons already discussed in previous sections. However, as already mentioned, further developments of this study include the consideration of the Cooling Degree Days (CDD) measure to estimate the building's energy demand for cooling as well.

Figure 21 illustrates post-retrofit annual costs and environmental impacts resulting for the as-built configuration and the eight retrofitting strategies in the three different sites, assuming a post-retrofit life of 20 years. The integrated intervention is still the most convenient strategy for all the three sites. However, for Reggio Calabria city, subjected to the highest seismic demands, the structural retrofitting option is convenient from the economic viewpoint, but not satisfactory in terms of carbon emissions, if compared to the other two options. On the other hand, for Cuneo, subjected to significant energy demands, the sole energy refurbishment and the integrated intervention are equally convenient, whilst the structural retrofitting option would not significantly improve the as-built configuration, since the seismic hazard is negligible. It is also noted that Cuneo is characterised by the highest expected annual costs and emissions, since energy consumption for heating is the major contributor to these values.

\subsection{Integrated economic and environmental building classification}

In Fig. 22, some of the results obtained above for Cuneo (namely; as-built configuration, external joint strengthening (JS), EPS panels for thermal insulation (TI), and RC walls coupled with EPS panels $(\mathrm{RCW}+\mathrm{TI})$ ) are superimposed on a potential seismic vulnerability-energy efficiency integrated classification scheme (currently featuring purely illustrative value ranges).

Fig. 22 Impact of some of the retrofitting options for the city of Cuneo on a potential integrated economic and environmental building classification schemeTI and RCW + TI interventions lead to a class upgrade of the building. Note: The correspondence between cost/emission value ranges and the colour scale in this plot is purely demonstrative

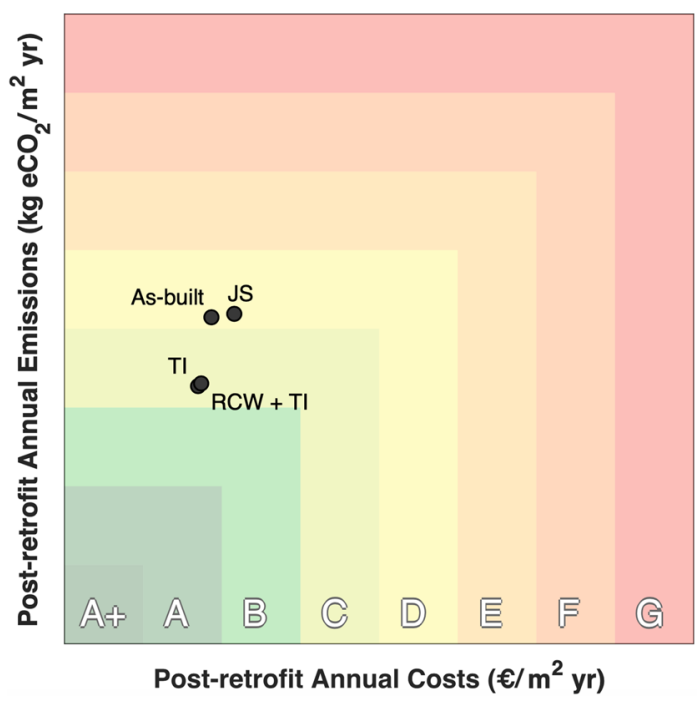


For this demonstrative example, it can be observed how the retrofitting options that lead to the highest reduction of economic losses and $\mathrm{CO}_{2}$ emissions (TI and $\mathrm{RCW}+\mathrm{TI}$ ), allow for a class upgrade of the building. It is clear to see how this proposed integrated economic and environmental building classification system could aid the process of identifying the optimal retrofitting strategy for a given building, and to encourage an integrated reduction of costs/impacts of the existing building stock (given that a reduction of costs or impacts alone would not always be sufficient for a class upgrade). That said, it is evident that defining value ranges of costs/impacts for classes is anything but a trivial task, given that those ranges would be strongly influenced by the geographic site being analysed. Extensive calibrating parametric studies are thus required before such a classification scheme may be defined and deployed.

\section{Conclusions}

The life cycle framework illustrated in the present work provides a viable and practical approach for a life cycle-based classification of buildings and for the identification of optimal building renovation strategies on the basis of economic and environmental impacts, considering both seismic vulnerability and energy efficiency of a given building. In this paper, a demonstrative application of the framework to a school building was discussed, investigating several retrofitting options, including structural strengthening, energy refurbishment, and integrated renovation strategies, and placing the building into different geographic locations.

The parametric study on the integrated reduction of economic and carbon emissions through the application of the life cycle framework proposed in Caruso et al. (2020a) showed that:

- The framework is readily applicable to any building of interest, performing each module of the framework through the methodology preferred by the user, e.g. seismic loss estimation can be performed equivalently through the FEMA P-58 procedure, or the Italian Guidelines conventional approach, or through any other existing methodology;

- Each retrofitting solution leads to different results in terms of annual costs and carbon emissions according to the summation in Eq. 1. External joints strengthening, even if coupled with a small insulation layer, did not seem to produce significant benefits neither in economic terms nor in environmental impacts. The introduction of new RC shear walls is comparable to the as-built configuration from both economic and environmental viewpoints, but it surely represents the most effective solution in terms of limitation of human losses. Sole energy refurbishments, i.e. the introduction of EPS insulation panels or the application of an ultra-thin ceramic thermal insulation layer, induce the highest benefits, especially if coupled with new RC walls, leading to an improvement of both seismic resistance and energy efficiency. It is noted that the retrofitting options considered here are mostly traditional ones, albeit the investigation of innovative techniques specifically aimed at the building's sustainability would also be of interest for future applications;

- Seismic and energy assessments demonstrated that annual costs and carbon emissions due to energy consumption for heating are higher than those due to seismic hazard, probably because of the architectural configuration of the school building 
under scrutiny, which features very large windows in its vertical envelope. However, it is worth noting that strong earthquakes have much severe consequences, if compared to energy consumption, that are not quantifiable economically or environmentally;

- Integrated renovation strategies are always convenient, especially in a long-term perspective, in terms of both life cycle costs and carbon emissions;

- The time of intervention may contribute significantly to reduce total annual costs and emissions; indeed, it is more effective to plan a retrofitting intervention after a shorter time from construction, as long as it produces a meaningful reduction in terms of energy consumption and seismic vulnerability in the post-retrofit operational phase;

- The geographic location quantitatively influences the estimates of monetary expenses and carbon emissions through the building life cycle, according to its seismic hazard and climatic conditions.

Developments that will be considered in the future with the objective of improving the calculations discussed in this work, and which are in addition to the methodological advancements already foreseen in Caruso et al. (2020a), include:

- Better estimates of costs and emissions associated to demolition of construction and retrofit materials, and the introduction of demolition and re-construction (according to up-to-date seismic and energy requirements) as a further alternative to the as-built configuration and the other retrofitting options;

- Energy performance assessments in dynamic conditions, accounting for the variability of outside temperature during a single day and during an entire month, leading to more accurate estimates, and the consideration of the energy demands for cooling as well;

- Retrofitting solutions customised for each geographic location considered, specifically related to the seismic hazard and the climatic conditions at the site of interest;

- Further investigations on alternative casualty models and on the integration of injured and homeless, considering not only inside-building risk but also outside-building risk due to falling debris or out-of-plane mechanisms of structural or non-structural components.

Finally, the application of this framework to other buildings typologies is also envisaged, with a view to investigate the possibility of developing a new integrated classification framework, based on life cycle costs and emissions, that would go beyond the traditional energy and seismic classification systems. Indeed, the results presented herein are valid for the specific case-study investigated, accounting for its architectural and structural characteristics, so different results are expected from the application of the framework to other buildings with different properties. In addition, the specificity of the case-study under scrutiny could also justify the relatively low variability observed in the results, due to a limited effectiveness of some of the retrofitting solutions considered.

Acknowledgements The authors would like to start by acknowledging the very insightful and useful discussions with Helen Crowley and Alessandra Marini on different aspects of this work. In addition, the authors acknowledge also the useful and informative discussions on seismic retrofitting with Nicolò Vignola, from Kerakoll. Finally, the constructive feedback of two anonymous reviewers, which have undoubtedly led to an improvement of the clarity and completeness of the manuscript, is also gratefully recognised.

Funding Open access funding provided by Università degli Studi di Pavia within the CRUI-CARE Agreement. This research was funded by the Italian Civil Protection Department (Dipartimento della Protezione 
Civile), within the framework of the ReLUIS-DPC 2019-2021 research project, more specifically its WP5 activities (focused on the development and verification of integrated seismic and energy retrofitting solutions).

\section{Declarations}

Conflict of interest The authors declare that they have no conflict of interest.

Open Access This article is licensed under a Creative Commons Attribution 4.0 International License, which permits use, sharing, adaptation, distribution and reproduction in any medium or format, as long as you give appropriate credit to the original author(s) and the source, provide a link to the Creative Commons licence, and indicate if changes were made. The images or other third party material in this article are included in the article's Creative Commons licence, unless indicated otherwise in a credit line to the material. If material is not included in the article's Creative Commons licence and your intended use is not permitted by statutory regulation or exceeds the permitted use, you will need to obtain permission directly from the copyright holder. To view a copy of this licence, visit http://creativecommons.org/licenses/by/4.0/.

\section{References}

Antoniou S, Pinho R (2004) Development and verification of a displacement-based adaptive pushover procedure. J Earthq Eng 8(05):643-661

Applied Technology Council (ATC) (2018a) Seismic performance assessment of buildings volume 1-methodology. Rep. No. FEMA P-58-1; Federal Emergency Management Agency (FEMA): Washington, DC, USA, 2018. https://femap58.atcouncil.org/reports. Accessed 22 Feb 2021

Applied Technology Council (ATC) (2018b) Seismic performance assessment of buildings, Volume 2-Implementation guide. Rep. No. FEMA P-58-2; Federal Emergency Management Agency (FEMA): Washington, DC, USA, 2018. https://femap58.atcouncil.org/reports. Accessed $22 \mathrm{Feb}$ 2021

Applied Technology Council (ATC) (2018c) Seismic Performance Assessment of Buildings, Volume 3Supporting Electronic Materials and Background Documentation. Rep. No. FEMA P-58-3; Federal Emergency Management Agency (FEMA): Washington, DC, USA, 2018. https://femap58.atcou ncil.org/reports. Accessed 22 Feb 2021

Applied Technology Council (ATC) (2018d) Seismic Performance Assessment of Buildings Volume 4Methodology for Assessing Environmental Impacts. Rep. No. FEMA P-58-4; Federal Emergency Management Agency (FEMA): Washington, DC, USA, 2018. https://femap58.atcouncil.org/repor ts. Accessed 22 Feb 2021

Baltzopoulos G, Baraschino R, Iervolino I, Vamvatsikos D (2017) SPO2FRAG: software for seismic fragility assessment based on static pushover. Bull Earthq Eng 15(10):4399-4425

Belleri A, Marini A (2016) Does seismic risk affect the environmental impact of existing buildings? Energy Build 110:149-158

Carnegie Mellon University Green Design Institute (CMUGDI) (2008) Free Economic Input-Output Life Cycle Assessment. http://www.eiolca.net/. Accessed 22 Feb 2021

Cardone D, Perrone G (2015) Developing fragility curves and loss functions for masonry infill walls. Earthq Struct 9(1):257-279

Cardone D (2016) Fragility curves and loss functions for RC structural components with smooth rebars. Earthq Struct 10(5):1181-1212

Cardone D, Perrone G (2017) Damage and loss assessment of pre-70 RC frame buildings with FEMA P-58. J Earthq Eng 21(1):23-61

Cardone D, Gesualdi G, Perrone G (2019) Cost-benefit analysis of alternative retrofit strategies for RC frame buildings. J Earthq Eng 23(2):208-241

Caruso M, Pinho R, Bianchi F, Cavalieri F, Lemmo MT (2020a) A life cycle framework for the identification of optimal building renovation strategies considering economic and environmental impacts. Sustainability 12(23): 10221

Caruso M, Bianchi F, Cavalieri F, Lemmo MT, Pinho R (2020b) Critical overview and application of integrated approaches for seismic loss estimation and environmental impact assessment. In: 
Proceedings of the RILEM Book Series of the 3rd RILEM Spring Convention and Conference (RSCC2020), Guimarães, Portugal, 10-14 March 2020 (in press)

Chioccarelli E, Cito P, Iervolino I, Giorgio M (2019) REASSESS V2.0: software for single-and multisite probabilistic seismic hazard analysis. Bull Earthq Eng 17(4):1769-1793

Coburn AW, Spence RJ, Pomonis A (1992) Factors determining human casualty levels in earthquakes: mortality prediction in building collapse. In: Proceedings of the 10th world conference on earthquake engineering, Madrid, Spain, 19-24 July 1992

Cosenza E, Del Vecchio C, Di Ludovico M, Dolce M, Moroni C, Prota A, Renzi E (2018) The Italian guidelines for seismic risk classification of constructions: technical principles and validation. Bull Earthq Eng 16(12):5905-5935

Crowley H, Colombi M, Borzi B, Faravelli M, Onida M, Lopez M, Polli D, Meroni F, Pinho R (2009) A comparison of seismic risk maps for Italy. Bull Earthq Eng 7(1):149-180

Del Vecchio C, Di Ludovico M, Prota A, Manfredi G (2015) Analytical model and design approach for FRP strengthening of non-conforming RC corner beam-column joints. Eng Struct 87:8-20

Dipartimento della Protezione Civile (DPC) (2018) National risk assessment: overview of the potential major disasters in Italy: seismic, volcanic, tsunami, hydro-geological/hydraulic and extreme weather, droughts and forest fire risks. Italian Civil Protection Department, Rome, Italy

Edilclima. EC700: Edilclima Engineering \& Software. https://www.edilclima.it/software-termotecnica/ prog-termotecnica-energetica/scheda/700. Accessed 22 Feb 2021

European Facility for Earthquake Hazard and Risk (EFEHR) European Seismic Risk Service. https://eurisk.eucentre.it/. Accessed 22 Feb 2021

Fajfar P (2000) A nonlinear analysis method for performance-based seismic design. Earthq spectra 16(3):573-592

Global Earthquake Model Foundation (GEM) (2018) Country Risk Profiles, Italy. https://www.globa lquakemodel.org/country-risk-profiles. Accessed $22 \mathrm{Feb} 2021$

Hammond GP, Jones CI (2008) Embodied energy and carbon in construction materials. Proc Inst Civ Eng-Energy 161(2):87-98

Leontief W (1986) Input-output economics. Oxford University Press

Mander JB, Priestley MJ, Park R (1988) Theoretical stress-strain model for confined concrete. J Struct Eng 114(8):1804-1826

Menegotto M, Pinto PE (1973) Method of analysis for cyclically loaded RC plane frames including changes in geometry and non-elastic behavior of elements under combined normal force and bending. In: Proceedings of IABSE symposium on resistance and ultimate deformability of structures acted on by well defined repeated loads, pp 15-22

Ministero delle Infrastrutture e dei Trasporti (MIT) (2015) Applicazione delle metodologie di calcolo delle prestazioni energetiche e definizione delle prescrizioni e dei requisiti minimi degli edifici: Decreto Ministeriale 26 giugno 2015. Gazzetta Ufficiale 162 del 15 Luglio 2015

Ministero delle Infrastrutture e dei Trasporti (MIT) (2017) Linee Guida per la Classificazione del Rischio Sismico delle Costruzioni: Decreto Ministeriale 65 del 7 Marzo 2017

Ministero delle Infrastrutture e dei Trasporti (MIT) (2018) Aggiornamento delle Norme Tecniche per le costruzioni: Decreto Ministeriale 17 Gennaio 2018. Gazzetta Ufficiale 42 del 20 Febbraio 2018

O'Reilly GJ, Perrone D, Fox M, Monteiro R, Filiatrault A (2018) Seismic assessment and loss estimation of existing school buildings in Italy. Eng Struct 168:142-162

O'Reilly GJ, Sullivan TJ (2018) Probabilistic seismic assessment and retrofit considerations for Italian RC frame buildings. Bull Earthq Eng 16(3):1447-1485

Pinho R, Bianchi F, Nascimbene R (2019) Valutazione sismica e tecniche di intervento per edifici esistenti in c.a., Costruzioni, Antisismica \& Normativa tecnica, Maggioli Editore

PRé Consultants. SimaPro I The World's Leading LCA Software. https://simapro.com/. Accessed 22 Feb 2021

Presidenza del Consiglio dei Ministri (PCM) (2016) LEGGE 11 dicembre 2016, n. 232. Bilancio di previsione dello Stato per l'anno finanziario 2017 e bilancio pluriennale per il triennio 2017-2019. Articolo 1, comma 2, lettera c). Gazzetta Ufficiale 297 del 21 Dicembre 2016

Prota A, Di Ludovico M, Del Vecchio C, Menna C, Frascadore R, Palladino F, Di Sarno L (2015) Caso studio: Scuola “G. Parozzani” - Scheda di sintesi interventi. Progetto DPC_ReLUIS 2019-2021 (WP5), ReLUIS Project

Ramirez CM (2009) Building-specific loss estimation methods \& tools for simplified performance-based earthquake engineering. Report no. 171, John A. Blume Earthquake Engineering Research Center, Stanford University, California

RÖFIX. RÖFIX EPS-F 031 GREY - Insulating panel for façades, grey. online: https://www.roefix.it/ prodotti. Accessed 22 Feb 2021 
SeismoSoft (2021) SeismoStruct 2021: A computer program for static and dynamic nonlinear analysis of framed structures. https://seismosoft.com/. Accessed 22 Feb 2021

Simonen K, Merrifield S, Almufti I, Strobel K, Tipler J (2015) Integrating environmental impacts as another measure of earthquake performance for tall buildings in high seismic zones. In: Structures Congress 2015, pp 933-944

Sousa L, Monteiro R (2018) Seismic retrofit options for non-structural building partition walls: Impact on loss estimation and cost-benefit analysis. Eng Struct 161:8-27

Sullivan TJ, Roldán R, Calvi GM (2015) Towards simplified displacement-based loss assessment and retrofit approaches, ReLUIS Project

UNI/TS 11300 (2010) Prestazioni energetiche degli edifici: Parte 3: Determinazione del fabbisogno di energia primaria e dei rendimenti per la climatizzazione estiva

UNI/TS 11300 (2012) Prestazioni energetiche degli edifici: Parte 4: Utilizzo di energie rinnovabili e di altri metodi di generazione per la climatizzazione invernale e per la produzione di acqua calda sanitaria

UNI/TS 11300 (2014) Prestazioni energetiche degli edifici: Parte 1: Determinazione del fabbisogno di energia termica dell'edificio per la climatizzazione estiva ed invernale

UNI/TS 11300 (2016a) Prestazioni energetiche degli edifici: Parte 5: Calcolo dell'energia primaria e dalla quota di energia da fonti rinnovabili

UNI/TS 11300 (2016b) Prestazioni energetiche degli edifici: Parte 6: Determinazione del fabbisogno di energia per ascensori e scale mobili

UNI/TS 11300 (2019) Prestazioni energetiche degli edifici: Parte 2: Determinazione del fabbisogno di energia primaria e dei rendimenti per la climatizzazione invernale, per la produzione di acqua calda sanitaria, per la ventilazione e per l'illuminazione in edifici non residenziali

VIRC Bronya Company Group. Bronya Façade NF - Superfine heat insulation. https://nano34.ru/en/ services/. Accessed 22 Feb 2021

Weber C, Matthews D, Venkatesh A, Costello C, Matthews H (2009) The 2002 US benchmark version of the economic input-output life cycle assessment (EIO-LCA) model. Green Design Institute at Carnegie Mellon University: Pittsburg, PA, USA, 2009; http://www.eiolca.net/docs/index.html. Accessed 22 Feb 2021

Zuccaro G, Cacace F (2011) Seismic casualty evaluation: The Italian model, an application to the L'Aquila 2009 event. In: Spence R, So E, Scawthorn C (eds) Human casualties in earthquakes: progress in modelling and mitigation. Advances in Natural and Technological Hazards Research; Springer: Dordrecht, The Netherlands, 2011; pp 171-184. ISBN 978-90-481-9455-1.

Publisher's Note Springer Nature remains neutral with regard to jurisdictional claims in published maps and institutional affiliations.

\title{
Authors and Affiliations
}

\section{Martina Caruso ${ }^{1} \cdot$ Rui Pinho ${ }^{2}$ - Federica Bianchi ${ }^{3} \cdot$ Francesco Cavalieri $^{3}$. Maria Teresa Lemmo ${ }^{4}$}

\author{
Martina Caruso \\ martina.caruso@iusspavia.it \\ Federica Bianchi \\ federica.bianchi@eucentre.it \\ Francesco Cavalieri \\ francesco.cavalieri@eucentre.it
}

Maria Teresa Lemmo

mariateresa.lemmo@pec.ording.pv.it

1 University School for Advanced Studies (IUSS), Piazza della Vittoria 15, 27100 Pavia, Italy

2 Department of Civil Engineering and Architecture, University of Pavia, Via Adolfo Ferrata 5, 27100 Pavia, Italy 
3 European Centre for Training and Research in Earthquake Engineering (EUCENTRE), Via Adolfo Ferrata 1, 27100 Pavia, Italy

4 Energy Efficiency Practitioner, 27100 Pavia, Italy 